\title{
Comparing scenarios of Canadian daily climate extremes derived using a weather generator
}

\author{
Budong Qian ${ }^{1, *}$, Samuel Gameda ${ }^{1}$, Reinder de Jong ${ }^{1}$, Pete Falloon ${ }^{2}$, Jemma Gornall ${ }^{2}$ \\ ${ }^{1}$ Eastern Cereal and Oilseed Research Centre, Agriculture and Agri-Food Canada, 960 Carling Ave, Ottawa, \\ Ontario K1A 0C6, Canada \\ ${ }^{2}$ Met Office Hadley Centre, Fitzroy Road, Exeter, Devon EX1 3PB, UK
}

\begin{abstract}
Stochastic weather generators are widely used for developing local climate scenarios from large-scale climate change scenarios simulated by GCMs. We used AAFC-WG, a stochastic weather generator developed at Agriculture and Agri-Food Canada (AAFC), to develop daily climate scenarios for the time period 2040-2069 for the agricultural regions of Canada, based on 4 climate change simulations conducted by global climate models CGCM3, HadCM3, ECHAM5/MPI-OM and CSIRO-Mk3.5. Annual and growing season (1 May to 30 September) extreme daily values of maximum temperature, minimum temperature and precipitation were estimated from these scenarios on fine grids $\left(0.5^{\circ}\right.$ latitude $\times 0.5^{\circ}$ longitude) and from direct daily global climate model (GCM) outputs on coarse grids $\left(\sim 2.8^{\circ}\right.$ latitude $\times 2.8^{\circ}$ longitude for CGCM3, $2.5^{\circ}$ latitude $\times 3.75^{\circ}$ longitude for HadCM3, and $\sim 1.865^{\circ}$ latitude $\times 1.875^{\circ}$ longitude for ECHAM5/MPI-OM and CSIRO-Mk3.5). Compared with the corresponding values from direct GCM outputs, the extremes from daily climate scenarios generated by the AAFC-WG provided more detail at the finer spatial scale. Although the spatial patterns of the changes in climate extremes were often similar, actual values of the extremes from localized scenarios may be more reliable than those from direct GCM outputs since climate extremes under the present climate were not often realistically reproduced by the GCMs studied here. It is understood that the actual values are important as they provide the basis for climate change impact studies and the development of adaptation strategies.
\end{abstract}

KEY WORDS: Climate scenarios $\cdot$ Climate extremes $\cdot$ Stochastic weather generator $\cdot$ Downscaling GCMs $\cdot$ Canada

\section{INTRODUCTION}

Global climate models (GCMs) are the most important tool for the extrapolation of climate change due to the enhanced greenhouse effect. Direct outputs from these models are available at a daily time scale; however, imperfect model specifications and coarse spatial resolutions may result in distortions at local sites. For example, GCMs tend to generate too many precipitation events and weaker intensities compared to observations at individual stations within the grid box (Mearns et al. 1990, 1995, Carter et al. 1994, Goddard et al. 2001). In addition, there are known weaknesses in GCMs when simulating climate variability, such as NAO and ENSO (IPCC 2007). Since most models used in climate change impact studies, such as hydrological and crop growth models, are weather sensitive, extreme climate events in the input climate scenarios can adversely affect crop growth and yield simulations (Mearns et al. 1996, Riha et al. 1996, Hansen \& Jones 2000, Baron et al. 2005). Therefore, correctly estimating climate extremes in modelled climate scenarios is crucial to the results of impact studies and the development of adaptation strategies.

Stochastic weather generators are statistical models that can generate synthetic weather data mimicking the weather data to which they have been calibrated (Hutchinson 1986, Wilks \& Wilby 1999). This technique has played an important role in developing climate scenarios for climate change impact studies (Wilks 
1992, Katz 1996, Mearns et al. 1997, Semenov \& Barrow 1997, Qian et al. 2005, Kilsby et al. 2007). Stochastic weather generators such as LARS-WG (Racsko et al. 1991, Semenov et al. 1998) and AAFC-WG (Hayhoe 2000, Qian et al. 2004) apply the changes in variance and mean of daily climate variables to perturb weather generator parameters for generating future climate scenarios (Semenov \& Barrow 2002, Qian et al. 2005). Such a capacity would apply to the generation of daily climate extremes as well, if stochastic weather generators are capable of reproducing observed frequency and intensity of climate extremes. Evaluations of the performance of LARS-WG and AAFC-WG have proven such a capacity (Semenov 2008, Qian et al. 2008), although some improvements in weather generation algorithms would enhance their capability in reproducing climate extremes.

Future climate scenarios developed by stochastic weather generators may show changes in climatic extremes similar to those obtained from direct GCM outputs. This is because changes in the statistics of daily climate variables (the same variables modelled by the weather generators, such as daily maximum and minimum temperatures and precipitation) on atmosphere-ocean GCM (AOGCM) grids are often used to perturb weather generator parameters (Semenov \& Barrow 2002, Qian et al. 2005) in order to generate future scenarios. However, the actual values of meteorological variables for extreme climate events from localized scenarios are anticipated to be more suitable and reliable for impact studies than those directly from GCM outputs, because sub-grid processes are parameterized, and detailed topography is not represented in GCMs. Generating information at a finer scale than the grid scale of the AOGCMs is often referred to as downscaling (Christensen et al. 2007). To distinguish the weather generator methods from dynamical downscaling (such as regional climate models) and other statistical downscaling methodologies that link local climate variables to large-scale atmospheric circulation (often represented by mean sea level pressures and geopotential heights), we refer to the weather generation of future climate scenarios as localization.

The objective of the present study was to compare scenarios of daily climate extremes derived from localized climate scenarios with direct GCM outputs. Emphasis was given to consistencies and differences between localized scenarios and direct GCM outputs, the strength and deficiency of the methodology for the development of the localized climate scenarios by the use of a stochastic weather generator, as well as uncertainties associated with GCMs in producing scenarios of daily climate extremes for Canadian agricultural regions for the time period 2040-2069 (approximately corresponding to a doubling of atmospheric $\mathrm{CO}_{2}$ concentration).

\section{DATA AND METHODS}

\subsection{Historical daily climate data}

A 30 yr (1961-1990) set of historical weather observations, including daily maximum temperature $\left(\mathrm{T}_{\max }\right)$, daily minimum temperature $\left(\mathrm{T}_{\min }\right)$ and daily precipitation $(\mathrm{P})$, was extracted from historical weather data sets archived at Agriculture and Agri-Food Canada (AAFC) for a total of 424 stations across agricultural regions of Canada.

\subsection{GCM data}

Data sets of climate change simulations conducted by 4 GCMs (CGCM3, HadCM3, ECHAM5/MPI-OM and CSIRO-Mk3) were used. CGCM3 is the third version of the coupled global climate model at the Canadian Centre for Climate Modelling and Analysis (CCCma) (Kim et al. 2002, 2003). HadCM3 is the third generation of the coupled AOGCM developed at the Hadley Centre for Climate Prediction and Research of the UK Met Office (Gordon et al. 2000). ECHAM5/ MPI-OM (Jungclaus et al. 2006) is the fifth generation of the general circulation model ECHAM5 coupled with ocean and land models, developed at the Max Planck Institute for Meteorology in Germany. The new CSIRO Mk3.5 model (Cai et al. 2003) is a coupled GCM developed at the Commonwealth Scientific and Industrial Research Organisation (CSIRO) in Australia.

The 20th Century Experiment (20C3M, an experiment run with greenhouse gases increasing as observed through the 20th century) for the time period 1961-1990 and a scenario run for the time period 2040-2069 forced by the IPCC Special Report on Emissions Scenarios (SRES) A2 emissions scenario (Nakicenovic \& Swart 2000) from each climate model were used as the baseline and future climate scenarios in the model. Since we were interested in the uncertainty associated with GCM simulations instead of that related to emission scenarios, only the simulations forced by IPCC SRES A2 were employed. Because of the huge amount of data at the daily time scale, only one member of the ensemble simulations was taken from each model. Daily outputs of CGCM3 were downloaded online from the CCCma website (www. cccma.ec.gc.ca/data/cgcm3/cgcm3.shtml). Daily outputs of HadCM3 were obtained from Hadley Centre through the Climate Impacts LINK project (Viner 1996). Daily outputs from ECHAM5/MPI-OM and CSIRO Mk3.5 were obtained from the World Climate Research Programme's Coupled Model Intercomparison Project phase 3 (CMIP3) multi-model data set (Meehl et al. 2007). Limited by data availability, daily 
GCM outputs for the future time period were for 20462065 from ECHAM5/MPI-OM and for 2041-2070 from CSIRO Mk3.5. These periods were deemed the same as the time period 2040-2069 for the other 2 GCMs. Daily maximum and minimum surface air temperatures, together with daily precipitation in the GCMs, were used.

\subsection{AAFC weather generator}

AAFC-WG (Hayhoe 2000) is a Richardson-type (Richardson 1981) stochastic weather generator. AAFCWG has shown acceptable reproduction of the probability distributions of daily $\mathrm{P}, \mathrm{T}_{\max }$ and $\mathrm{T}_{\min }$ for most cases, as well as some important agro-climatic indices that are indicators of climate conditions for crop growth and production (Qian et al. 2004). In addition, Qian et al. (2008) showed that AAFC-WG performed well in reproducing extreme daily values for diverse Canadian climates. An evaluation was also conducted on the capability of AAFC-WG for generating future climate scenarios under climate change and optimal approaches for perturbing its parameters reflecting climate change based on experiments with historical climate data (Qian et al. 2005). The evaluation indicated that AAFC-WG performed well in producing climate scenarios under a changing/changed climate. Therefore, to the extent that the changes in statistics of weather variables from climate change simulations by GCMs are reliable, future climate scenarios generated by AAFC-WG can be reliable for agricultural applications.

\subsection{Generation of synthetic weather data for the baseline period}

Synthetic weather data including daily $\mathrm{T}_{\max }, \mathrm{T}_{\min }$ and $P$ for the baseline period 1961-1990 were generated by the AAFC-WG for agricultural regions of Canada at a spatial resolution of $0.5^{\circ}$ latitude $\times 0.5^{\circ}$ longitude. British Columbia was not included because of its complex topography. To generate synthetic weather data for the baseline period 1961-1990, the following steps were used:

(A1) The AAFC-WG was calibrated with historical weather data (1961-1990) at each of 31 representative stations (from the full data set of 424 stations), covering diverse climates and geographical regions across Canadian agricultural areas. The parameters for the AAFC-WG include second-order transition probabilities for wet and dry days, empirical distributions of standardized daily $\mathrm{T}_{\max }, \mathrm{T}_{\min }$ and log-transformed daily precipitation amounts on wet days, the monthly mean values and variances of these weather variables, and correlation matrices used in the first-order multivariate autoregression model. Details of the parameters used by the AAFC-WG can be found in Hayhoe (2000) and Qian et al. (2004).

(A2) All weather generator parameters, except the empirical distributions and correlation matrices indicated above, were then computed from the historical weather data (1961-1990) at each of 424 stations across the agricultural region. These parameters were then interpolated to each of the $0.5^{\circ}$ latitude $\times 0.5^{\circ}$ longitude grid points by inverse distance squared weighting.

(A3) Synthetic weather data were generated for each of the $0.5^{\circ}$ latitude $\times 0.5^{\circ}$ longitude grid points by the AAFC-WG using the parameters obtained in Step A2 for the grid points together with the empirical distributions of standardized daily $\mathrm{T}_{\max }, \mathrm{T}_{\min }$ and log-transformed daily precipitation amounts on wet days and the correlation matrices calibrated for the representative station near the grid point. Since empirical distributions employed in AAFC-WG were estimated from standardized daily $\mathrm{T}_{\max }, \mathrm{T}_{\min }$ and log-transformed daily precipitation amounts on wet days, it was assumed that the empirical distributions estimated from a representative station were applicable to the nearby grid points under a similar climate. This assumption was also applied to the correlation matrices that were used in the first-order multivariate autoregression model for generating standardized $\mathrm{T}_{\max }$ and $\mathrm{T}_{\min }$.

\subsection{Generation of future climate scenarios}

Four separate sets of future climate scenarios for the time period 2040-2069 were generated by perturbing the weather generator parameters based on climate changes simulated by CGCM3, HadCM3, ECHAM5/ MPI-OM and CSIRO Mk3.5 forced with the IPCC SRES A2 emissions scenario. Hereafter, the 4 scenarios are referred to as CGCM3, HadCM3, ECHAM and CSIRO. The following steps were taken to generate future scenarios of daily $T_{\max }, T_{\min }$ and $P$ for a GCM:

(B1) All the parameters in Step A2 were computed for the 2 time periods, 1961-1990 and 2040-2069, from daily GCM outputs for $\mathrm{T}_{\max }, \mathrm{T}_{\min }$ and $\mathrm{P}$ at GCM grid points. The differences and ratios of the parameters between these 2 periods were calculated for each GCM grid point. Details of the parameters we used can be found in Qian et al. (2005).

(B2) The differences and ratios were interpolated to each of the $0.5^{\circ}$ latitude $\times 0.5^{\circ}$ longitude grid points from 4 surrounding GCM grid points. They were used as climate change scenarios for modifying the weather 
generator parameters at the $0.5^{\circ}$ latitude $\times 0.5^{\circ}$ longitude grid scale.

(B3) The differences and ratios for each of the $0.5^{\circ}$ latitude $\times 0.5^{\circ}$ longitude grid points from Step B2 were applied to parameters estimated from the observed baseline climate in Step A2 to form a new set of parameters for the future period 2040-2069 based on the climate change simulated by the GCM. Weather generator parameters and the approaches used to modify these parameters are fully described in Qian et al. (2005).

(B4) Future scenarios of daily $\mathrm{T}_{\max }, \mathrm{T}_{\min }$ and $\mathrm{P}$ were then generated by using the new set of parameters in Step B3 for a $0.5^{\circ}$ latitude $\times 0.5^{\circ}$ longitude grid point, together with the empirical distributions of standardized daily $\mathrm{T}_{\max }, \mathrm{T}_{\min }$ and log-transformed daily precipitation amounts on wet days and the correlation matrices calibrated for the representative station near the grid point.

Since a stochastic weather generator can generate a weather series of any length, we generated 300 yr long scenarios, a reasonable length for a good estimation of extreme values (e.g. 50 yr return values). Using the differences and ratios, it was assumed that changes in statistics of climate variables would be more reliable than the actual values from direct GCM outputs. The changes in the statistics of climate variables from GCM simulations were also assumed to be consistent over a considerable spatial scale. Considering the global scale of warming due to the enhanced greenhouse effect, the latter of the assumptions seemed reasonable. Observed changes in temperature and precipitation in Canada (Zhang et al. 2000, 2001) provide evidence to support this assumption.

\subsection{Extreme daily values}

Climate extremes can have critical impacts on crop growth and agricultural production. Extremely high/ low temperatures and heavy rains during the growing season are among such extremes (e.g. Falloon \& Betts in press). The growing season in Canada refers, in general, to the time period between 1 May and 30 September. Climate extremes outside the growing season are also of interest in non-agricultural sectors such as human health and the living environment. For example, extreme cold temperatures in winter affect the occurence of frostbite in humans and survival rate of insects. Future scenarios of climate extremes presented in the present study are annual and growing season maximal daily $\mathrm{T}_{\max }$ minimal daily $\mathrm{T}_{\min }$ and maximal daily $\mathrm{P}$, based on their 50 yr return values. The 50 yr return values are the extreme values that are expected to be exceeded approximately once every 50 yr. Annual and growing season extreme daily val- ues were derived from daily data for the baseline period 1961-1990 and the future period 2040-2069.

The generalized extreme value (GEV) distribution (Coles 2001) was fitted to both the baseline and the future series of yearly maxima for the estimation of return values. One of the advantages of the use of the GEV distribution was the possibility of obtaining a confidence interval for a return value. This was useful for the verification of whether the return values estimated for the future and the baseline climates are significantly different. The shape parameter $\kappa$, the location parameter $\xi$ and the scale parameter $\alpha$ of the GEV distribution were estimated by the method of L-moments (Hosking 1990, 1992). The $T$-year return values $X_{T}$ were then estimated from the quantile function of the GEV distribution as:

$$
X_{T}=\left\{\begin{array}{l}
\hat{\xi}+\hat{\alpha}\left\{1-[-\ln (1-1 / T)]^{\hat{\kappa}}\right\} / \hat{\kappa}, \hat{\kappa} \neq 0 \\
\hat{\xi}-\hat{\alpha} \ln [-\ln (1-1 / T)], \hat{\kappa}=0
\end{array}\right.
$$

The sampling uncertainty of the estimates was determined by a bootstrap procedure (Kharin \& Zwiers 2005) in which 'new' samples of yearly values of extremes were generated from the original sample by random resampling with replacement. In this procedure, 1000 new samples of size $30 \mathrm{yr}$ length for direct GCM outputs (300 for data generated by the weather generator) were generated by this resampling approach. A return value was then estimated from each generated sample by fitting and inverting a GEV distribution as derived above. The lower and upper $10 \%$ percentiles of the resulting collection of return value estimates were then used as the $80 \%$ confidence interval for the true $T$-year return value. If the $80 \%$ confidence interval of a return value estimated for the future climate did not overlap with the $80 \%$ confidence interval of the corresponding return value estimated for the baseline climate at the same grid point (or location), the return value estimated for the future climate was considered statistically different from that of the baseline climate, at the $\sim 10 \%$ significance level (based on Monte Carlo simulations, Kharin \& Zwiers 2005). The resampling approach estimated uncertainty in sampling errors and internal variability but did not take into account other sources of uncertainty such as model uncertainty and forcing scenario uncertainty.

In summary, for each $0.5^{\circ}$ grid point, the 50 yr return values of the climate extremes were derived from $300 \mathrm{yr}$ long daily synthetic climate data generated by AAFCWG for the baseline climate (1961-1990). Their corresponding future values were also estimated from four 300 yr long daily climate scenarios for the future period (2040-2069) generated by the AAFC-WG with climate changes simulated by CGCM3, HadCM3, ECHAM and CSIRO models, with the forcing scenario IPCC SRES A2. Such climate scenarios are herein referred to as the lo- 


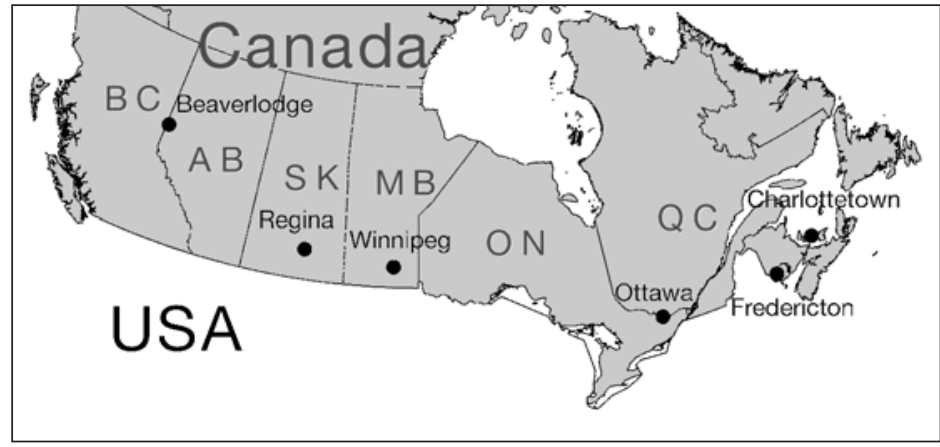

Fig. 1. Canadian stations for comparisons and provinces on the Canadian prairies (AB: Alberta; SK: Saskatchewan; MB: Manitoba) and Central Canada (ON: Ontario; QC: Quebec). British Columbia (BC) was not included due to its complex topography

calized climate scenarios. Similarly, the 50 yr return values of the selected extremes were also derived from direct GCM outputs on approximately $2.8^{\circ}$ latitude $\times 2.8^{\circ}$ longitude grids for $\mathrm{CGCM} 3,2.5^{\circ}$ latitude $\times 3.75^{\circ}$ longitude grids for HadCM3, and roughly $1.865^{\circ}$ latitude $\times$ $1.875^{\circ}$ longitude grids for ECHAM5/MPI-OM and CSIRO-Mk3.5, for 2 periods: 1961-1990 for the modelled baseline climates and 2040-2069 for the modelled future climates, based on daily outputs. Extreme values estimated from measured climate data for 1961-1990 at some stations (Fig. 1) were also presented, in comparison with the observed baseline values and future scenarios at their nearest grid points. However, the way station data can be compared with GCM outputs at grid points depends on whether a grid-box or grid-point approach was adopted (Skelly \& Henderson-Sellers 1996). A gridbox approach assumes that the GCM values are areal averages in grid boxes resulting in a smoother climate surface than the observed climate surface. However, the values in the scenarios generated by the weather generator were for the $0.5^{\circ} \times 0.5^{\circ}$ grid points, instead of averages for the grid box. This should be kept in mind when the results from the comparisons are discussed.

\section{RESULTS}

In the interests of space, only $50 \mathrm{yr}$ return values for annual maximal daily $\mathrm{T}_{\max }\left(\mathrm{T}_{\mathrm{x}-\mathrm{a}}\right)$, annual minimal daily $\mathrm{T}_{\text {min }}\left(\mathrm{T}_{\mathrm{n}-\mathrm{a}}\right)$, growing season minimal daily $\mathrm{T}_{\text {min }}\left(\mathrm{T}_{\mathrm{n} \text {-gs }}\right)$ and growing season maximal daily $\mathrm{P}\left(\mathrm{P}_{\mathrm{x}-\mathrm{gs}}\right)$ are presented. Since annual maximal daily $\mathrm{T}_{\max }$ most likely occurs during the growing season, $\mathrm{T}_{\mathrm{x}-\mathrm{a}}$ was a good indicator of extreme hot weather for both the entire year and the growing season. Low temperatures in the growing season are generally much higher than the annual minimal daily $\mathrm{T}_{\min }$. As such, $\mathrm{T}_{\mathrm{n} \text {-a }}$ and $\mathrm{T}_{\mathrm{n} \text {-gs }}$ are presented together in order to reflect extreme weather for the entire year and relatively cold conditions for crop growth during the growing season. Heavy precipitation may occur in any season, but maximal daily precipitation is more likely to occur in summer, associated with convective systems, especially on the Canadian prairies. $\mathrm{P}_{\mathrm{x} \text {-gs }}$ values are presented; however, annual maximal daily precipitation was found to be similar to the $\mathrm{P}_{\mathrm{x} \text {-gs }}$ in the present study, especially on the prairies.

\subsection{Annual maximal daily maximum temperature $\left(\mathrm{T}_{\mathrm{x}-\mathrm{a}}\right)$}

Except in Atlantic Canada, Quebec and northern Alberta, the 50 yr return values of $\mathrm{T}_{\mathrm{x} \text {-a }}$ were $>36^{\circ} \mathrm{C}$ in most areas for the baseline period (Fig. 2a). Values $>38^{\circ} \mathrm{C}$ were seen in a large area on the prairies, and the highest value was $>42^{\circ} \mathrm{C}$. Based on the localized CGCM3 scenario for 2040-2069 (Fig. 2b), $\mathrm{T}_{\mathrm{x}-\mathrm{a}}$ can be expected to reach $>46^{\circ} \mathrm{C}$ in the southern part of the prairies, and $>40^{\circ} \mathrm{C}$ in the majority of the remainder of the prairies. Changes were significant everywhere, with an increase ranging from 1 to $6^{\circ} \mathrm{C}$ (Fig. 2c). Larger changes were projected for the southern part of the prairies compared with other regions. The localized scenario of HadCM3 showed 50 yr return values even higher than CGCM3, especially in Ontario and Quebec (Fig. 2d). Based on HadCM3, the changes were much larger in the southern prairies and southern Ontario (Fig. 2e), doubling those based on CGCM3. Similar changes (Fig. 2f,i) were seen from the localized scenario of ECHAM, although values $>44^{\circ} \mathrm{C}$ were projected in a smaller region of the prairies as compared to CGCM3. A very similar pattern was also projected by the localized scenario of CSIRO (Fig. 2j,k).

The 50 yr return values of $\mathrm{T}_{\mathrm{x}-\mathrm{a}}$ estimated from direct GCM outputs of CGCM3 for 1961-1990 were often about $2^{\circ} \mathrm{C}$ higher than the observed values (Fig. 3a). The scenarios for 2040-2069 also showed higher $50 \mathrm{yr}$ return values (Fig. $3 b$ ) than those in the localized scenario (Fig. 2b) in most areas, and the changes (Fig. 3c) were not significant on some coarse grids. Overestimation in direct GCM outputs of HadCM3 was also found for the baseline climate (Fig. 3d), especially in southern and western Ontario. The overestimation resulted in much higher values for the future period in these regions (Fig. 3e) compared to the localized scenario of HadCM3. However, the projected changes were not statistically significant in the model on many coarse grids (Fig. 3f). An underestimation of 8 to $10^{\circ} \mathrm{C}$ was found on the prairies and in southern Ontario for the baseline climate in direct GCM outputs of ECHAM (Fig. 3g), resulting in lower values (Fig. 3h) than the lo- 


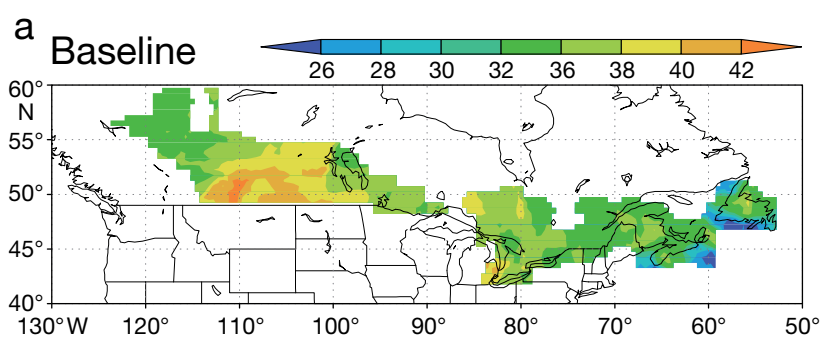

GCM3

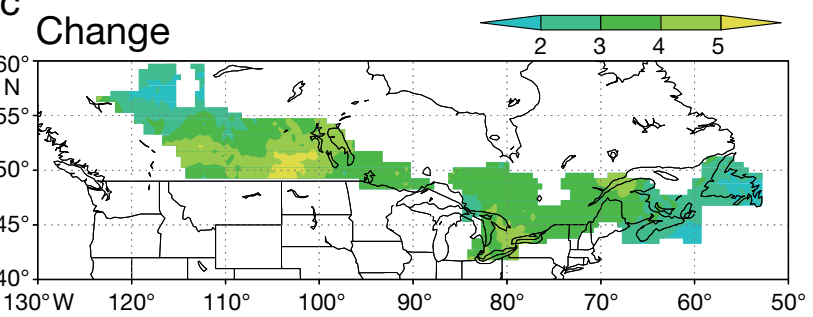

HadCM3

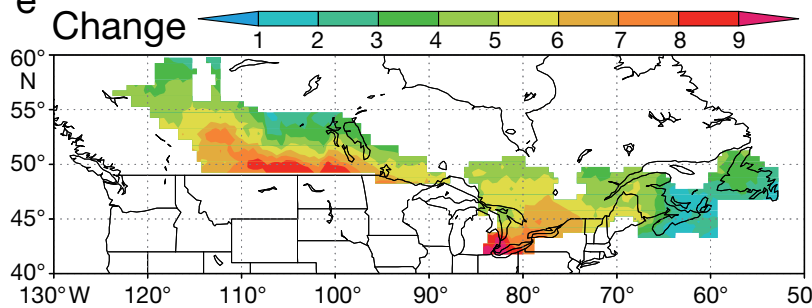

ECHAM

Change

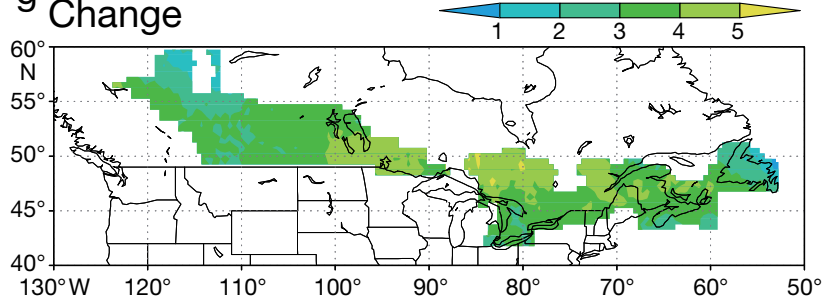

CSIRO

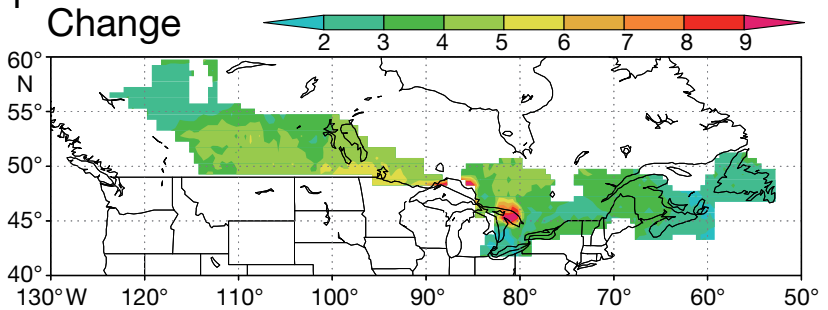

calized scenario for the future climate. Changes in the 50 yr return values in direct GCM outputs of ECHAM were also not significant on some GCM grids (Fig. 3i). In contrast to ECHAM, overestimations were seen from direct GCM outputs of CSIRO in most regions for the baseline climate (Fig. 3j), and consequently much higher return values in direct GCM outputs than the localized scenario for the future (Fig. 3k). The changes were significant on most GCM grids in CSIRO (Fig. 31).

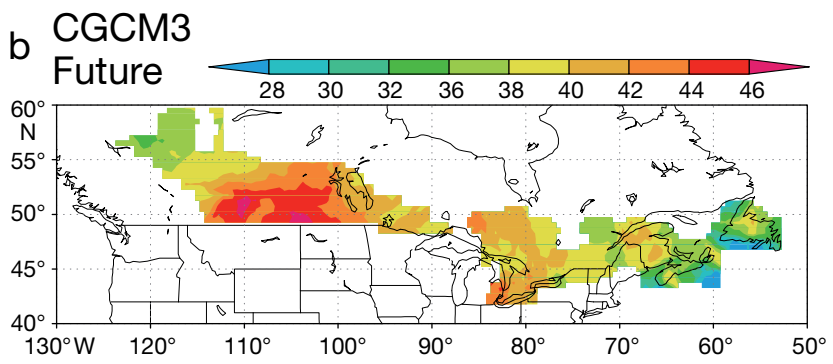

d HadCM3
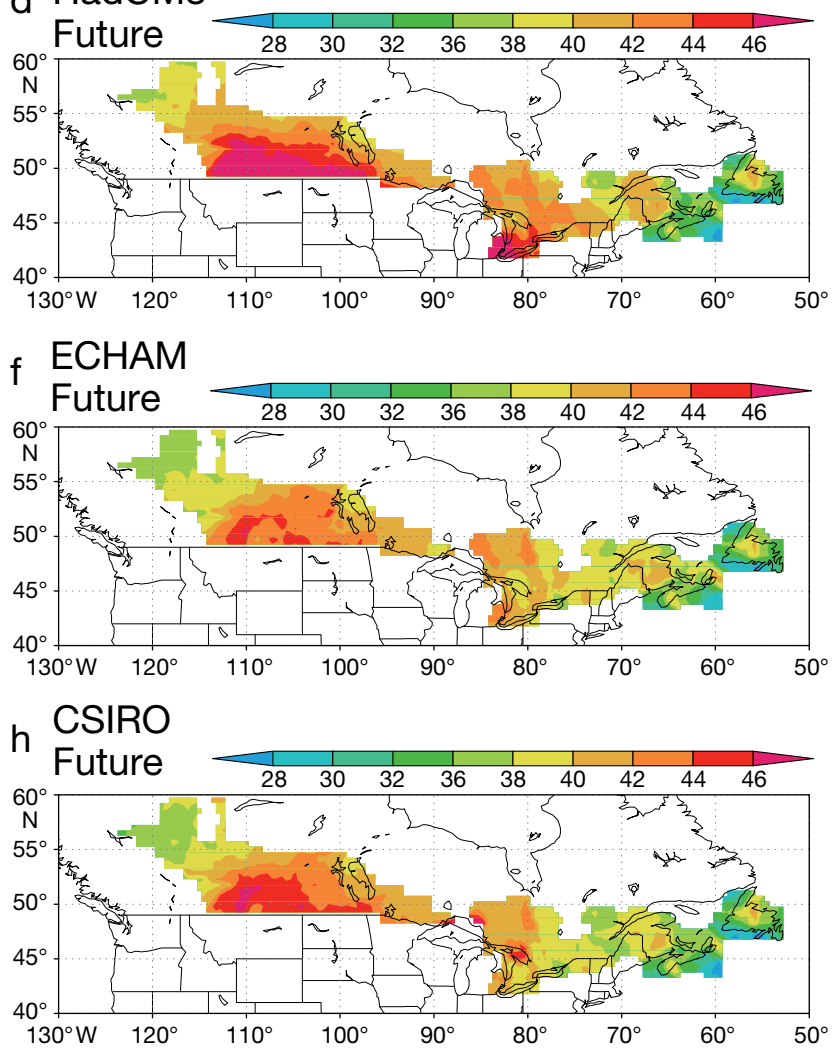

Fig. 2. 50 yr return values $\left({ }^{\circ} \mathrm{C}\right)$ of annual maximal daily maximum temperature for the baseline period (1961-1990) and the localized scenarios of the future period (2040-2069) based on CGCM3, HadCM3, ECHAM and CSIRO as well as the difference between the future and the baseline periods for each scenario. Only statistically significant changes are shown. The same rule was applied to other maps

The return values of $\mathrm{T}_{\mathrm{x}-\mathrm{a}}$ estimated from station data at selected locations across the agricultural regions were often close to those at nearby fine grids estimated from synthetic data generated by the weather generator for the baseline period (Table 1). The return values at nearby GCM grids from direct GCM outputs of CGCM3 for the baseline period were either lower or higher than those at nearby fine grids, depending upon the location. The under- and overestimation of 
CGCM3

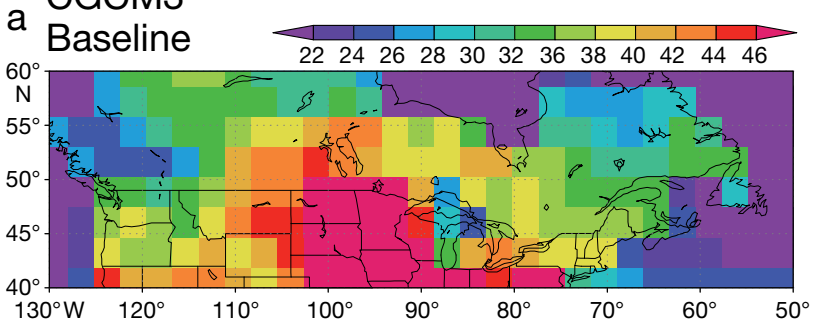

CGCM3
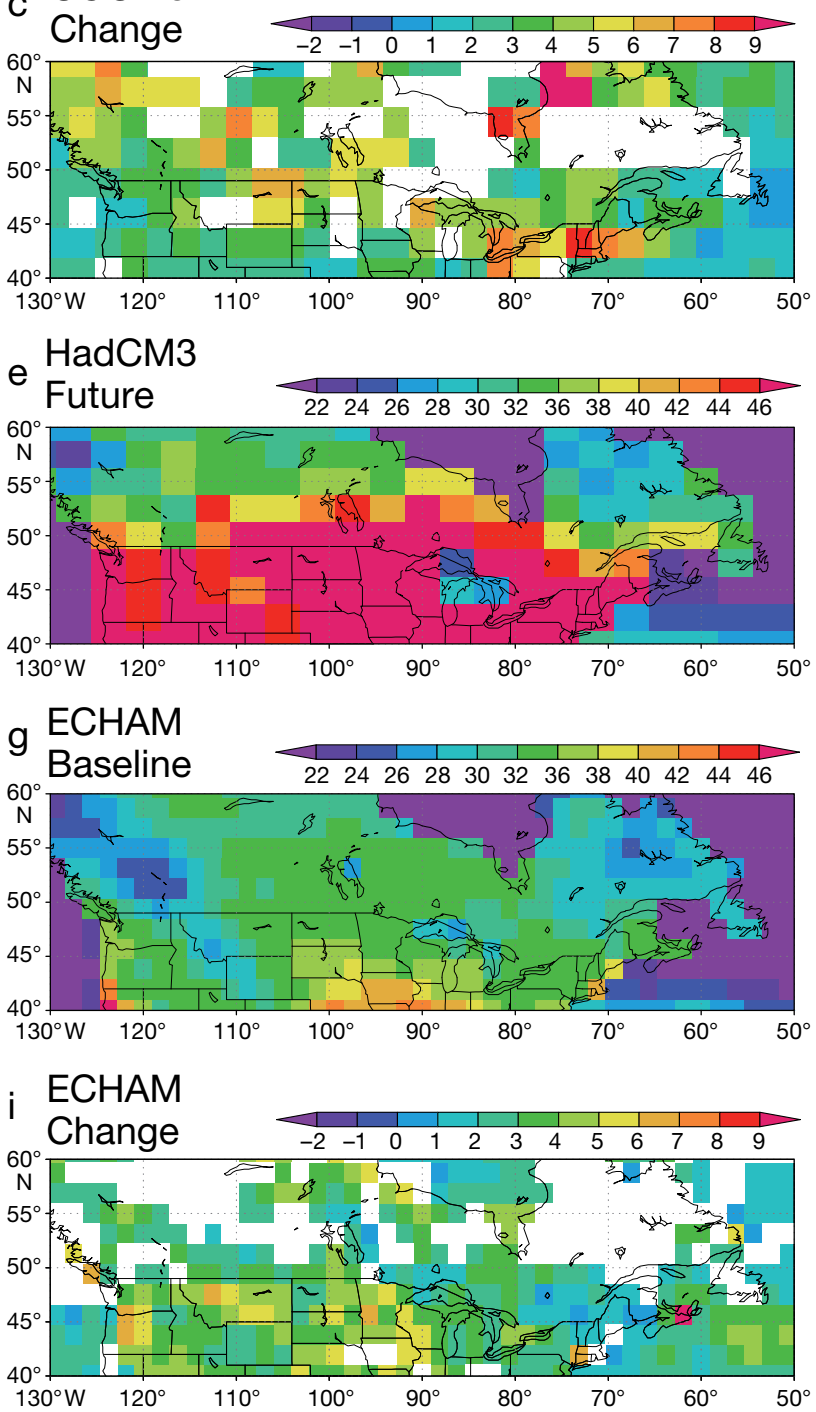

\section{k CSIRO}

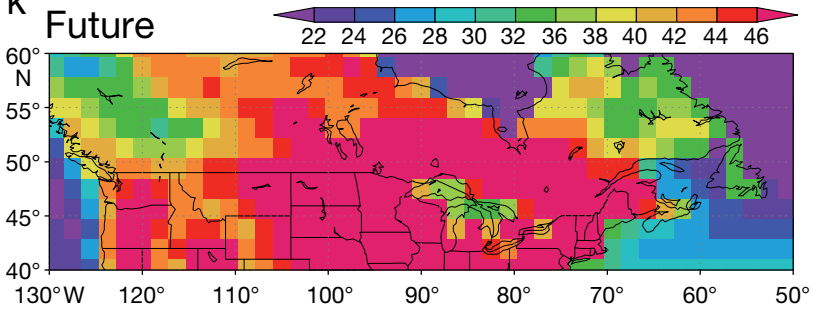

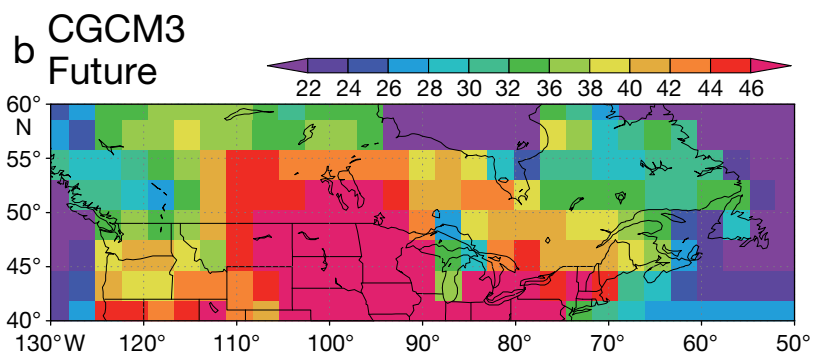
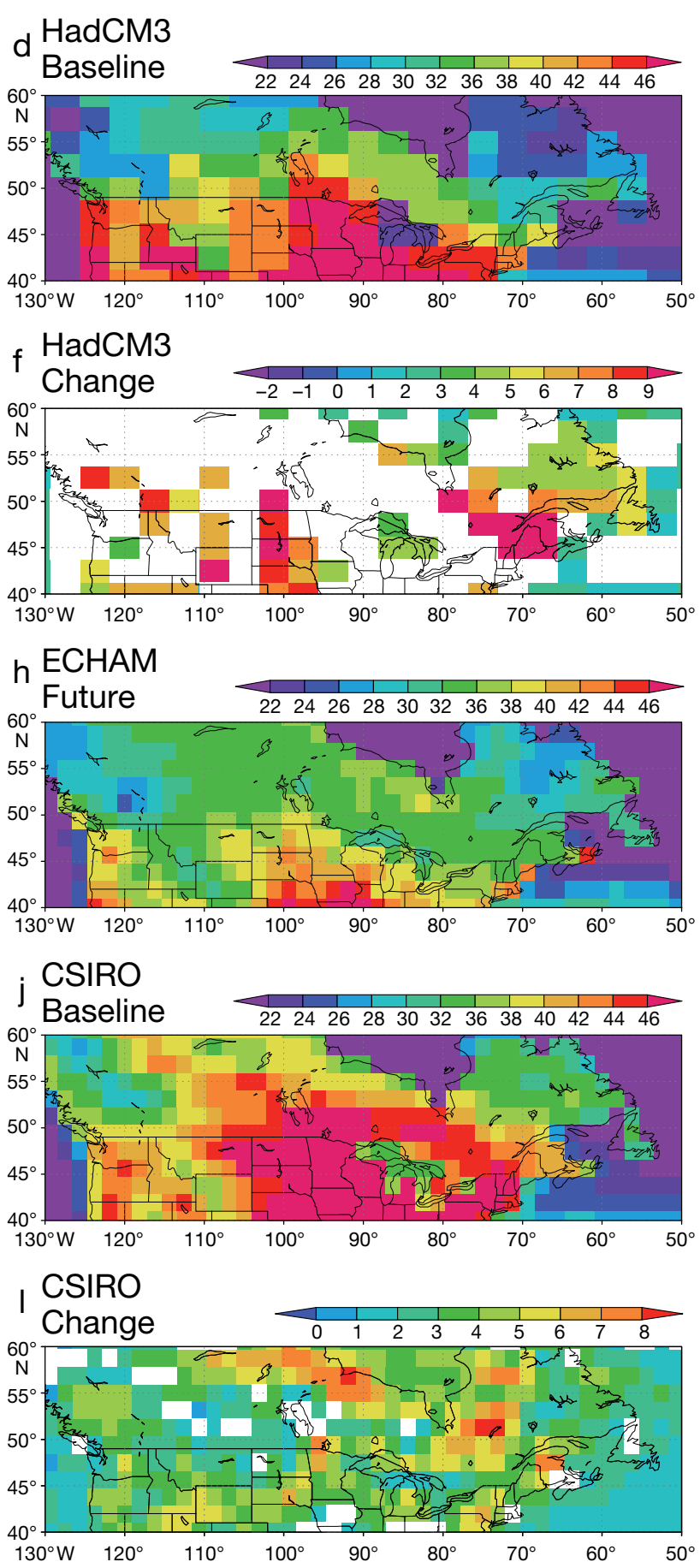

Fig. 3. As Fig. 2, but derived from direct GCM outputs 


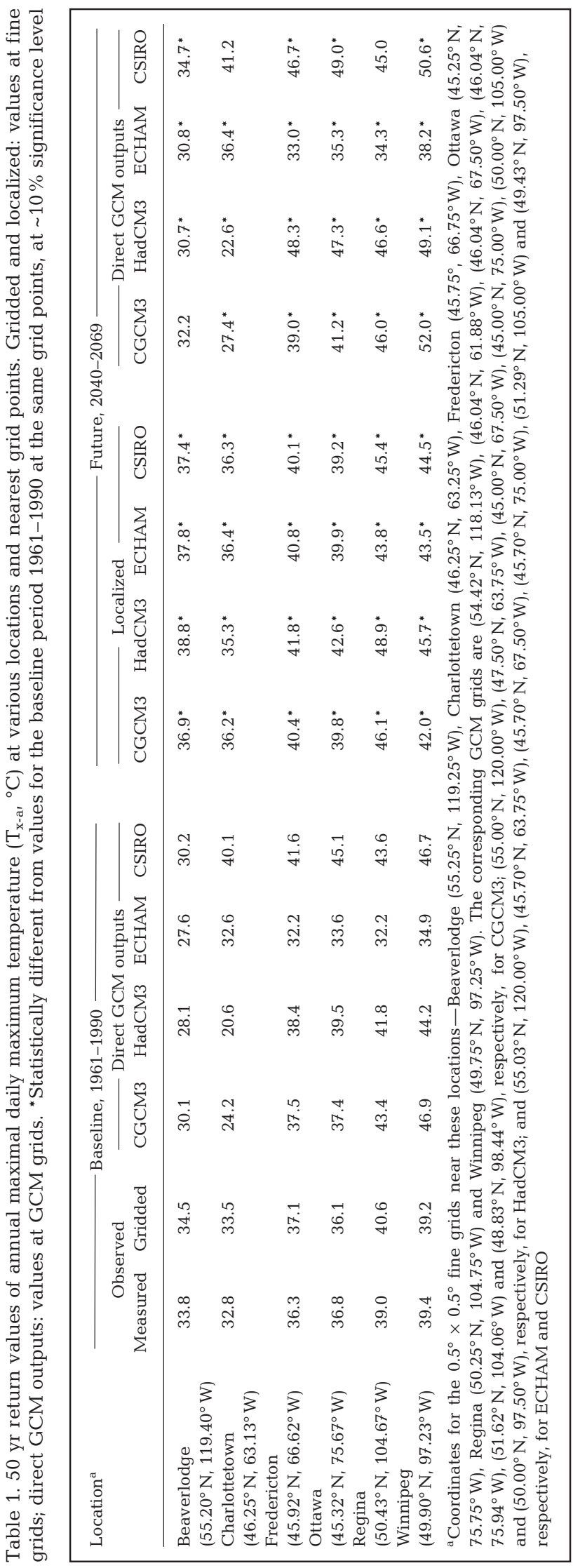

the baseline climate were consequently reflected by lower or higher future values from direct CGCM3 outputs as compared to localized ones. A similar situation was observed for HadCM3; however, an overestimated return value for the baseline climate in direct GCM outputs did not necessarily lead to higher future values in direct GCM outputs in comparison to localized ones. For example, the localized HadCM3 value $\left(48.9^{\circ} \mathrm{C}\right)$ near Regina was higher than that $\left(46.6^{\circ} \mathrm{C}\right)$ from the direct GCM output, although the baseline value $\left(41.8^{\circ} \mathrm{C}\right)$ from direct HadCM3 output was higher than the observed gridded value $\left(40.6^{\circ} \mathrm{C}\right)$. This implies that GCM biases may not be constant through the 20C3M experiment and future projections. Underestimation of $\mathrm{T}_{\mathrm{x}-\mathrm{a}}$ was often seen from direct GCM output of ECHAM, while overestimation was found for CSIRO. All return values across the 6 locations in the localized scenarios for 2040-2069 were significantly different from those for 1961-1990, for all 4 models. Additionally, the range of future values reflecting the model difference in the localized scenarios was much smaller than that in direct GCM outputs for the same location. For the case of Winnipeg, for example, future values range from 42.0 to $45.7^{\circ} \mathrm{C}$ in the localized scenarios, but ranged from 38.2 to $52.0^{\circ} \mathrm{C}$ in direct GCM outputs.

\subsection{Annual minimal daily minimum temperature $\left(T_{n-a}\right)$}

The 50 yr return values of $\mathrm{T}_{\mathrm{n} \text {-a }}$ were as low as under $-45^{\circ} \mathrm{C}$ on the prairies and in northern Ontario and above $-45^{\circ} \mathrm{C}$ in most of eastern Canada, with the highest values in Atlantic Canada for the baseline period 1961-1990 (Fig. 4a). Significant increases were foreseen in the localized scenarios of CGCM3 for 20402069 , with $\mathrm{T}_{\text {n-a }}$ values 6 to $9^{\circ} \mathrm{C}$ higher than the baseline period for most areas on the prairies and in eastern Canada (Fig. 4b,c). The increases resulted in a pattern where the return values on the prairies in the future resemble those observed in central Canada for the baseline period, while the future values in central Canada were comparable to observed values in Atlantic Canada. Changes for the central part of the prairies were not significant, but an increase of 3 to $5^{\circ} \mathrm{C}$ was projected in eastern Canada based on the localized scenarios of HadCM3 (Fig. 4d,e). HadCM3 is the only one of the 4 models that projected a decrease in $\mathrm{T}_{\mathrm{n}-\mathrm{a}}$ (i.e. colder) in the western part of the prairies. The projections in the localized scenario of ECHAM (Fig. 4f) were in general similar to those of HadCM3, but warmer on the prairies and in eastern Canada (Fig. 4g). There would be an increase of 1 to $5^{\circ} \mathrm{C}$ in the western part of the prairies with ECHAM instead of a decrease of $2^{\circ} \mathrm{C}$ with HadCM3. The ECHAM scenario 

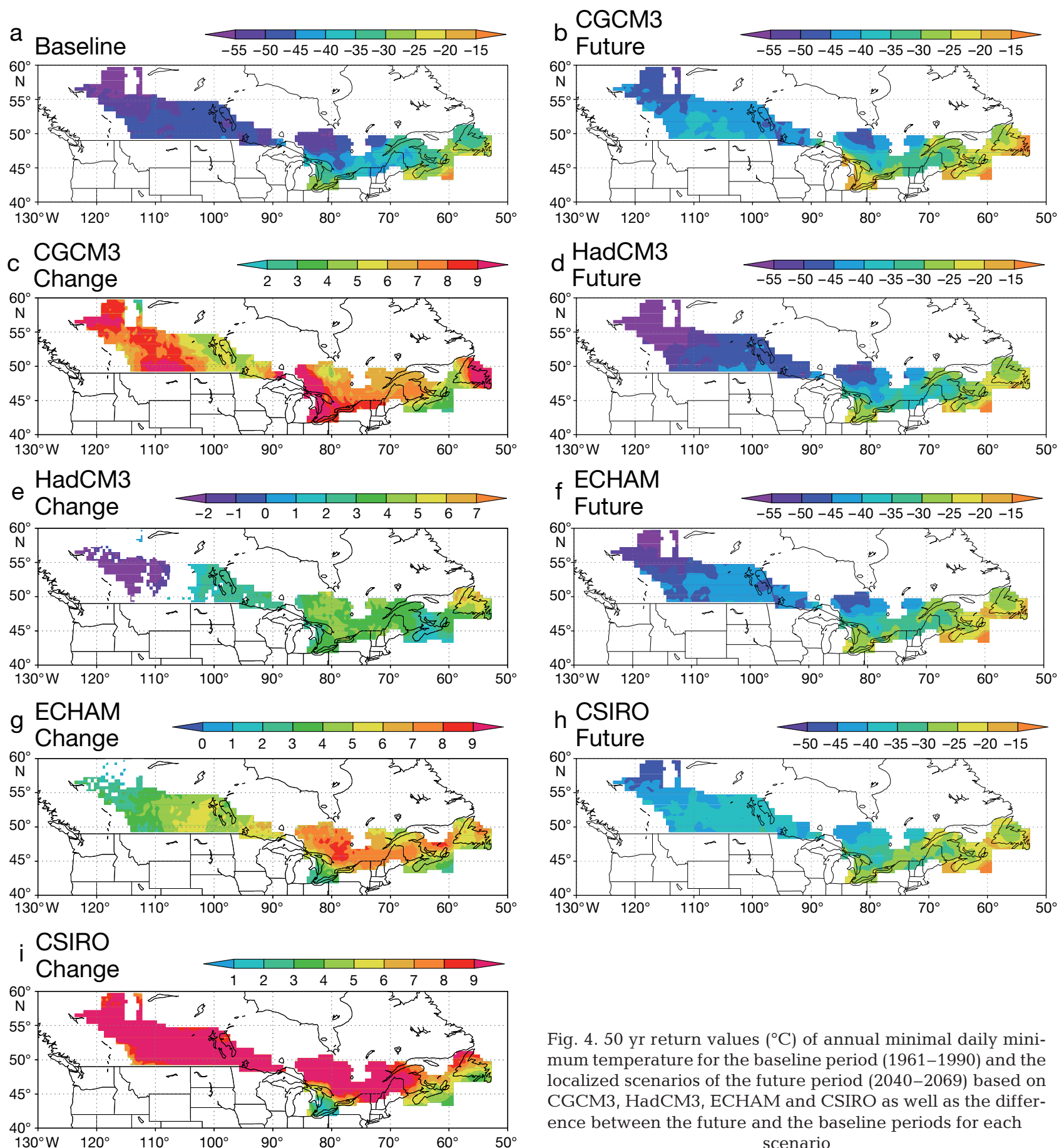

Fig. 4. 50 yr return values $\left({ }^{\circ} \mathrm{C}\right)$ of annual minimal daily minimum temperature for the baseline period (1961-1990) and the localized scenarios of the future period (2040-2069) based on CGCM3, HadCM3, ECHAM and CSIRO as well as the difference between the future and the baseline periods for each scenario

was still cooler than the CGCM3 and CSIRO scenarios. The CSIRO scenario (Fig. 4h) was similar to but warmer than the CGCM3 scenario, as an increase of $>8^{\circ} \mathrm{C}$ was projected almost everywhere (Fig. 4i).

The 50 yr return values of $\mathrm{T}_{\mathrm{n}-\mathrm{a}}$ estimated from direct CGCM3 outputs for 1961-1990 (Fig. 5a) were fairly close to the observed ones; therefore, future values estimated from direct CGCM3 outputs (Fig. 5b) were mostly similar to those in the localized scenario. Differences could still be found between the localized scenario and direct GCM outputs, such as lower values in the southern prairies and southern Ontario in direct CGCM3 outputs as compared to localized ones. Projected changes in direct CGCM3 outputs (Fig. 5c) seemed more scattered than those in the localized scenario. The estimations from direct HadCM3 outputs 

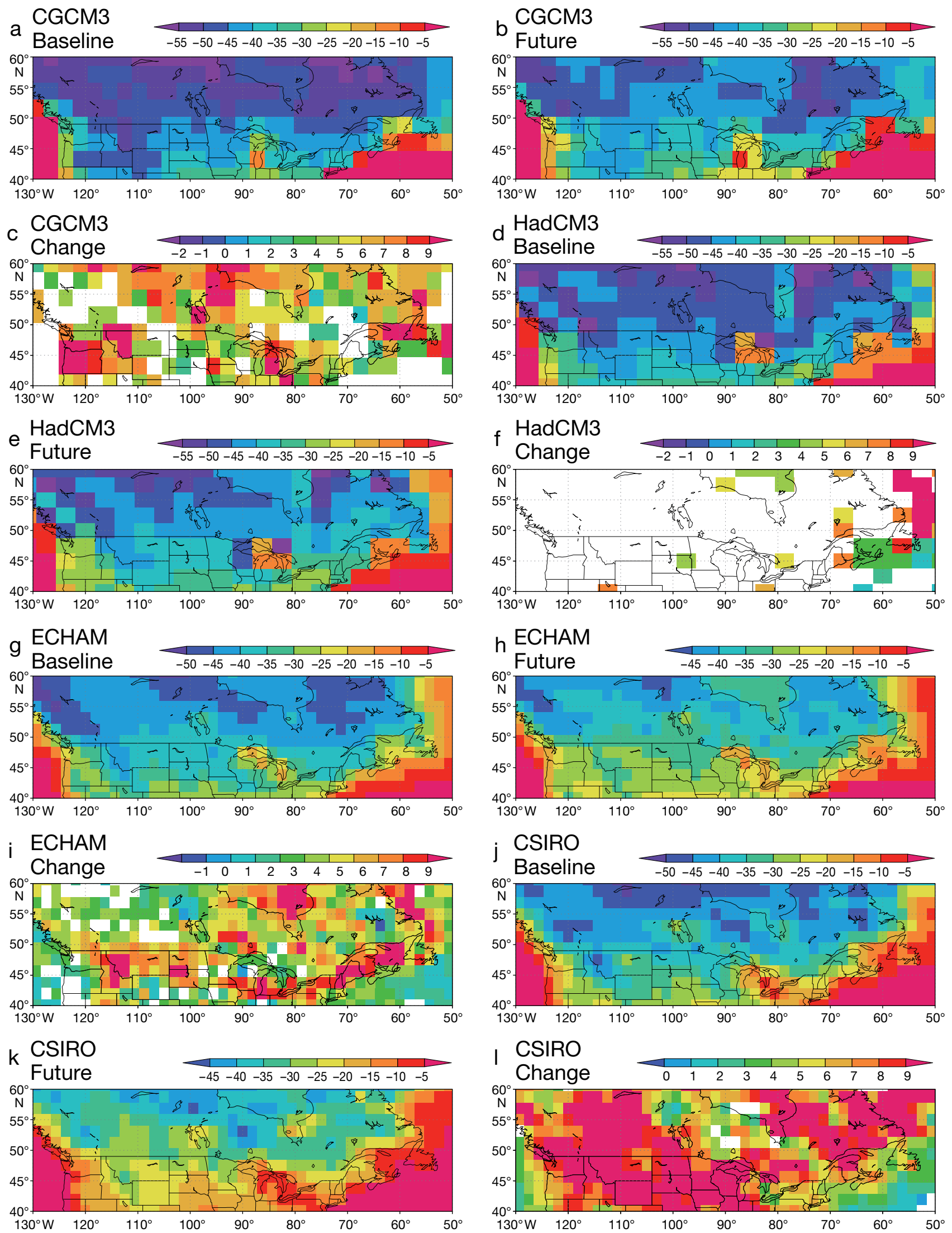

Fig. 5. As Fig. 4, but derived from direct GCM outputs 


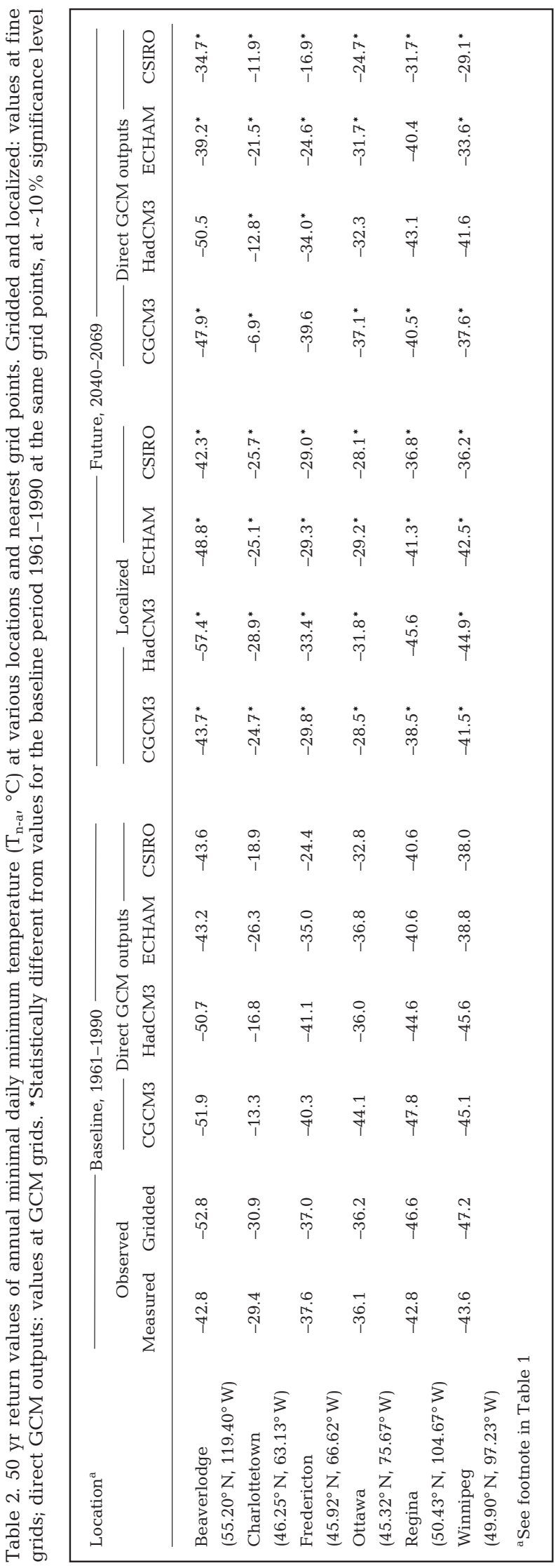

(Fig. 5d) were close to the observed baseline climate. The future scenarios from direct HadCM3 outputs (Fig. 5e) were also comparable to those from the localized scenario, although they were higher in the western prairies. Changes in direct GCM outputs (Fig. 5f) were statistically significant for very few coarse grids. The simulated values on the prairies for the baseline climate in ECHAM (Fig. $5 \mathrm{~g}$ ) were $>10^{\circ} \mathrm{C}$ higher than the observed ones; such overestimations were carried over to future scenarios, resulting in higher values in direct GCM outputs (Fig. 5h) than in the localized scenario. Smoother changes were seen in the localized scenario than in direct ECHAM outputs (Fig. 5i). Overestimations were also evident in direct CSIRO outputs for the baseline climate (Fig. 5j), resulting in a much warmer projection (Fig. 5k) compared to the localized scenario of CSIRO.

The return values of $\mathrm{T}_{\mathrm{n}-\mathrm{a}}$ estimated from station data were not as close to those at nearby fine grids as for $\mathrm{T}_{\mathrm{x}-\mathrm{a}}$. The values at Charlottetown, Fredericton and Ottawa matched well, but were much lower than the station values at 3 locations on the prairies (Table 2). This was consistent with our previous finding, that a more extreme value in the synthetic data generated by the weather generator AAFC-WG often caused the mismatch of return values for extreme low temperatures (Qian et al. 2008). The values derived from direct GCM outputs of CGCM3 at nearby GCM grids for the baseline period were much lower than the ones at the stations or at the fine grids, except for Charlottetown, where the nearby GCM grid represented the ocean rather than land. The values from HadCM3 were relatively closer to the observed data, again except for Charlottetown. ECHAM and CSIRO performed similarly without apparent advantages over the other 2 GCMs. Significant increases in $\mathrm{T}_{\mathrm{n}-\mathrm{a}}$ at all locations in the 4 localized scenarios were seen, except at Beaverlodge and Regina in the HadCM3 scenario. The return values for the future period derived from the localized scenarios were often significantly different from those for the baseline period, but fewer cases were seen from direct GCM outputs. Similar to the case of $\mathrm{T}_{\mathrm{x}-\mathrm{a}}$, future values were more consistent among the GCMs in the localized scenarios than in direct GCM outputs.

\subsection{Growing season minimal daily minimum temperature $\left(T_{n-g s}\right)$}

The 50 yr return values of $\mathrm{T}_{\mathrm{n} \text {-gs }}$ for the baseline period were below $-10^{\circ} \mathrm{C}$ on the prairies and between -4 and $-10^{\circ} \mathrm{C}$ in eastern Canada, except for the northern part of Ontario (Fig. 6a). An increase in $\mathrm{T}_{\mathrm{n} \text {-gs, }}$ usually $<5^{\circ} \mathrm{C}$, was estimated from the localized scenarios of CGCM3 (Fig. 6b,c) and HadCM3 (Fig. 6d,e). 


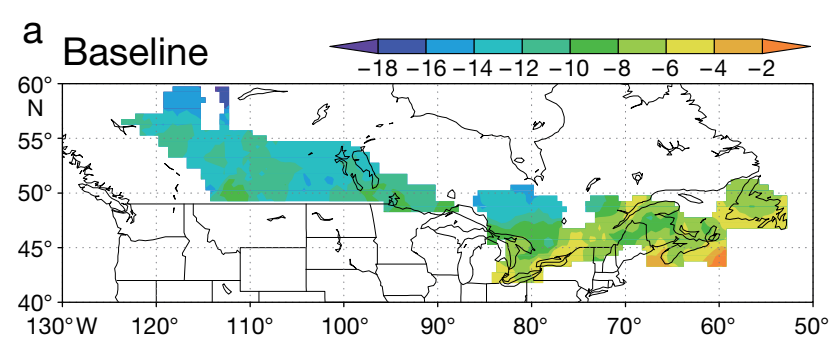

\section{CGCM3 Change}

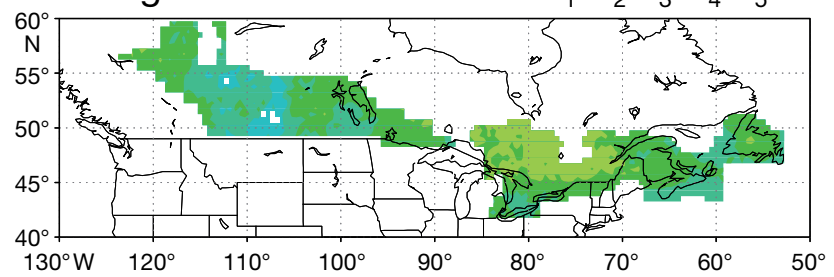

$\mathrm{HadCM} 3$

e Change

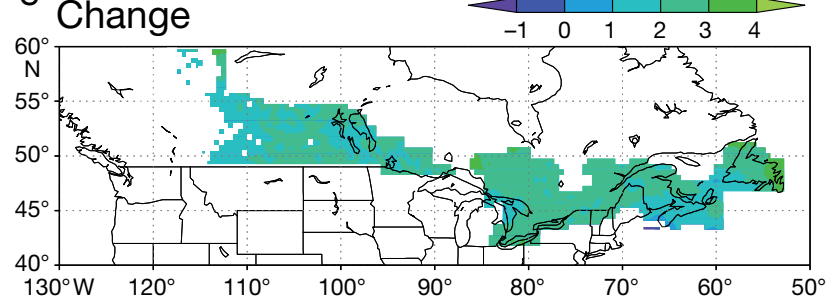

ECHAM

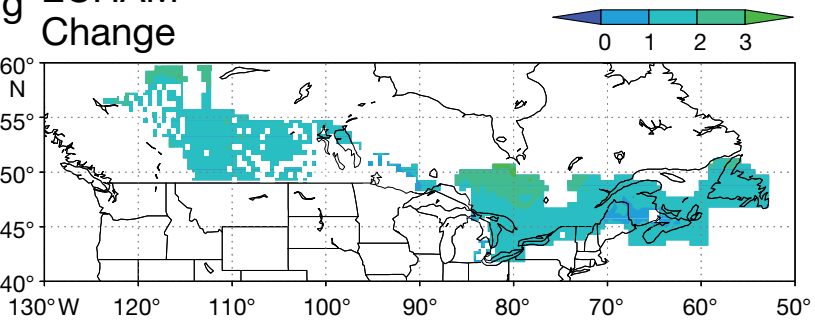

CSIRO

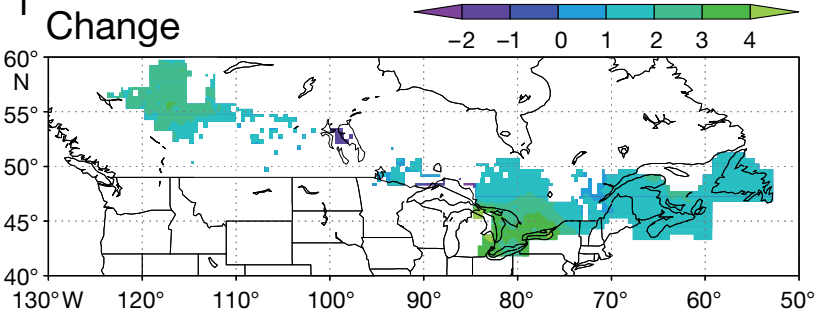

The changes were fairly consistent in magnitude and much smaller than the changes in $\mathrm{T}_{\mathrm{n}-\mathrm{a}}$. The estimated changes from the localized scenarios of ECHAM and CSIRO were similar but even smaller and insignificant in western Canada (Fig. 6f-i). All 4 scenarios projected that the extreme low temperature during the growing season would not significantly increase in the future. Potential changes in growing season length under a future climate were not considered in the present study.
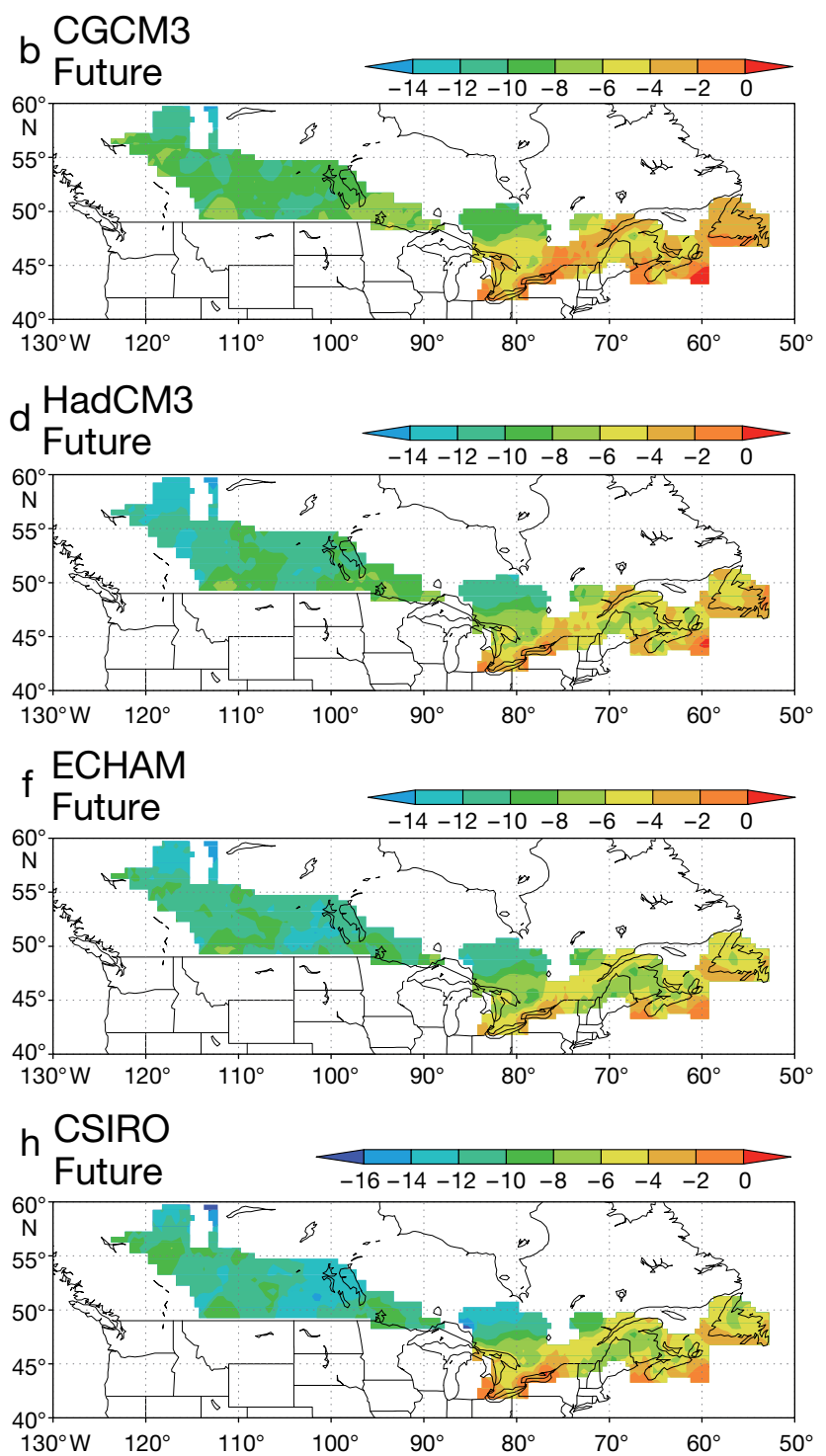

Fig. 6. $50 \mathrm{yr}$ return values $\left({ }^{\circ} \mathrm{C}\right)$ of growing season minimal daily minimum temperature for the baseline period (19611990) and the localized scenarios of the future period (2040-2069) based on CGCM3, HadCM3, ECHAM and CSIRO as well as the difference between the future and the baseline periods for each scenario

The 50 yr return values of $\mathrm{T}_{\mathrm{n} \text {-gs }}$ estimated from direct CGCM3 outputs (Fig. 7a) for the baseline climate were often lower than the observed ones. However, future values from direct CGCM3 outputs (Fig. 7b) were similar to those estimated from the localized scenario (except in eastern Canada), because the estimated changes in direct CGCM3 outputs (Fig. 7c) were often larger than those derived from the localized scenarios. The 50 yr return values derived from direct HadCM3 


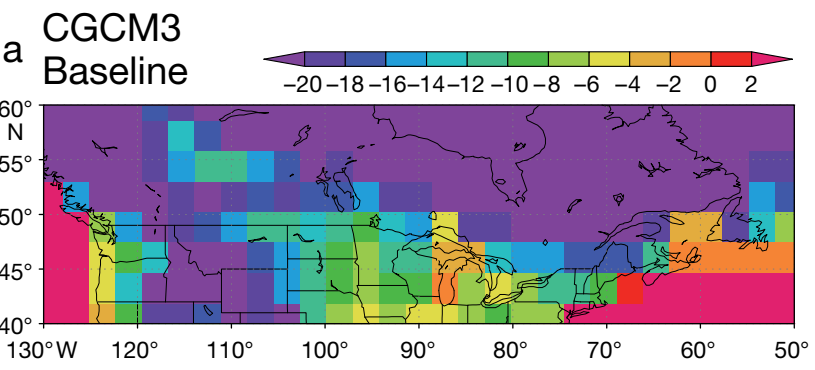

CGCM3
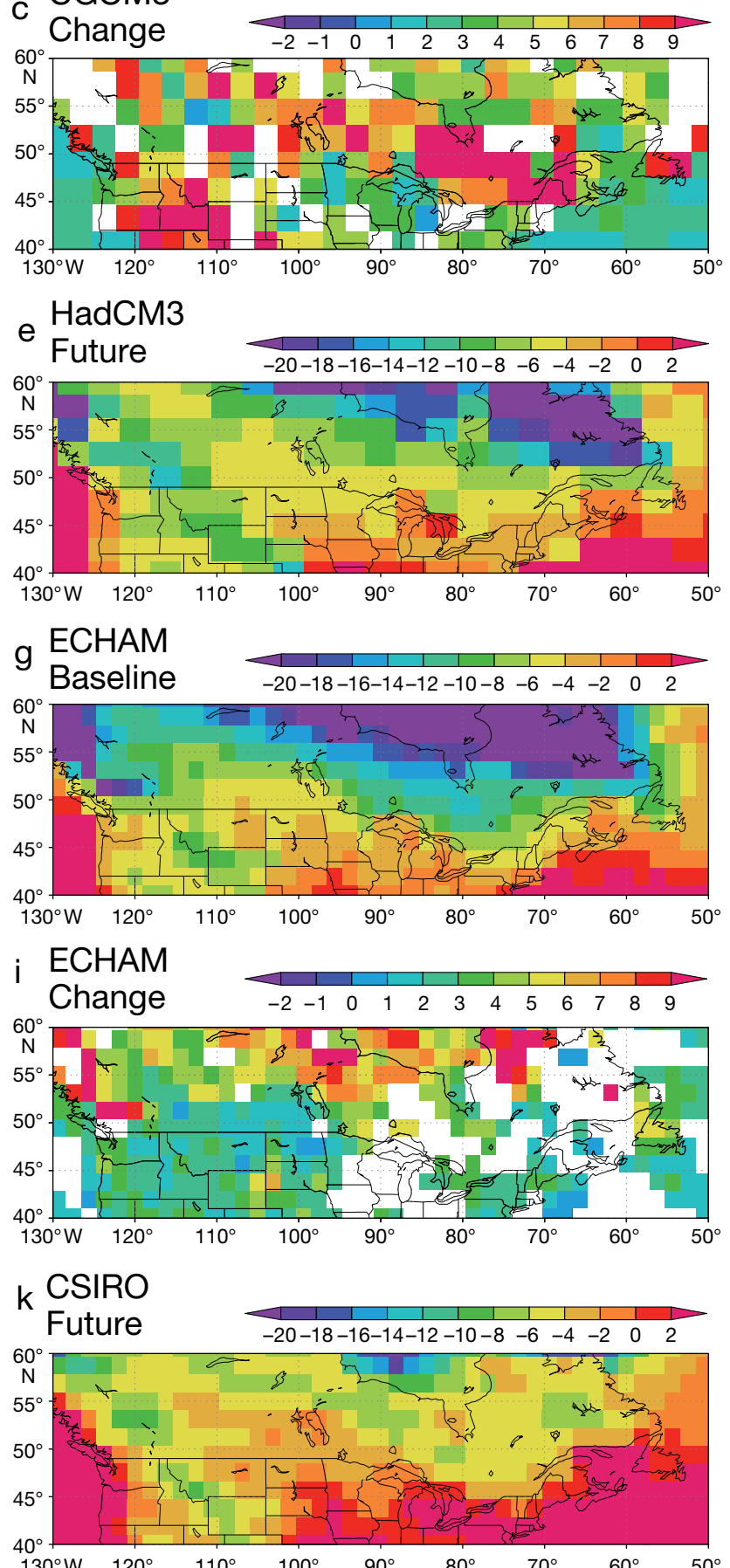
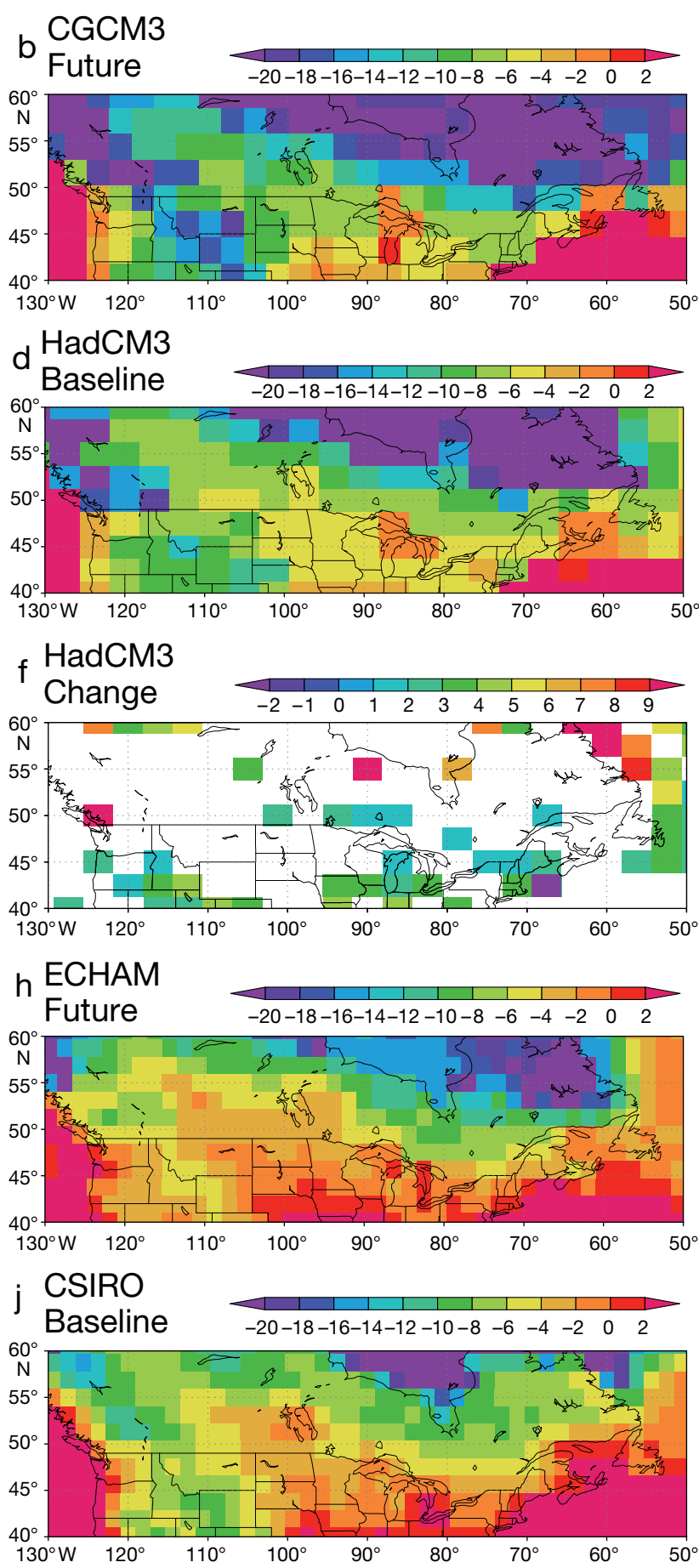

CSIRO

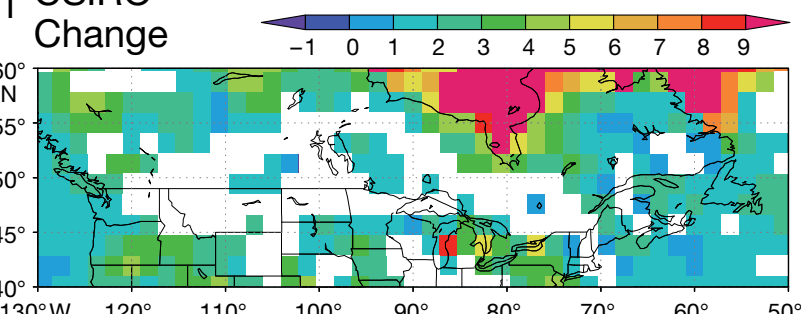

Fig. 7. As Fig. 6, but derived from direct GCM outputs 


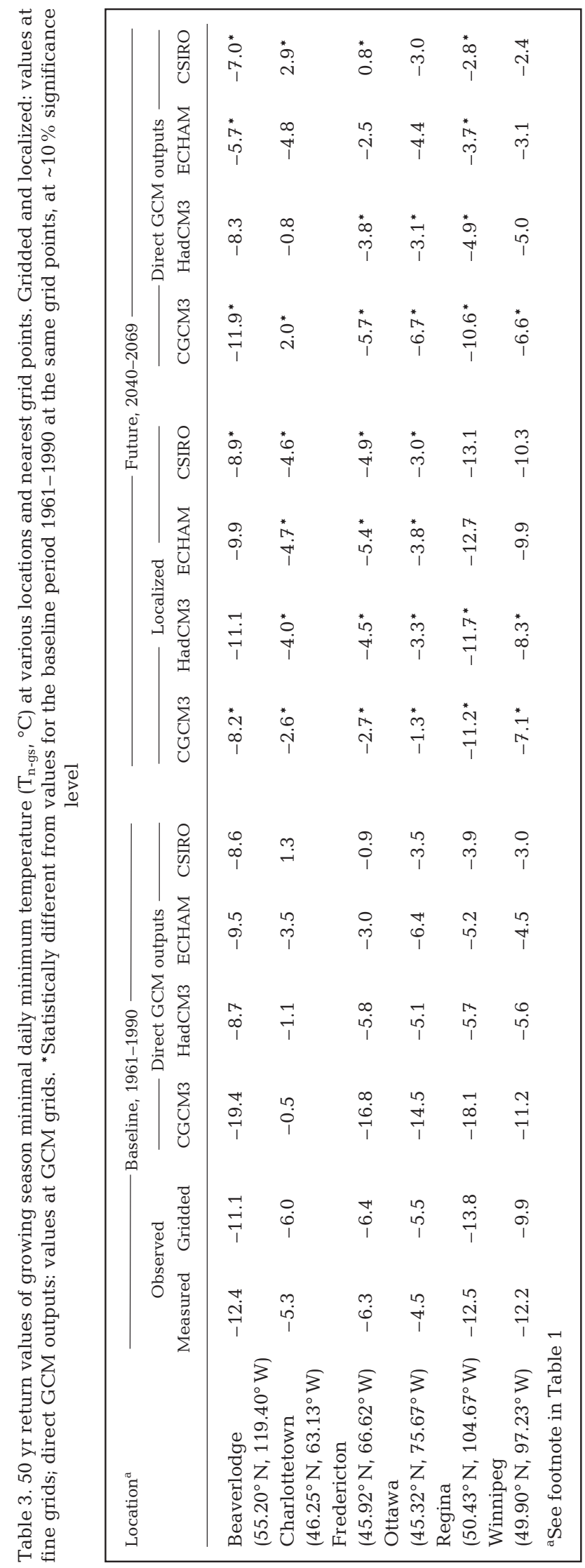

outputs for the baseline climate (Fig. 7d) were higher than the observed ones, especially on the prairies, resulting in higher future values (Fig. 7e) than those in the localized scenario. The changes in the $50 \mathrm{yr}$ return values in direct HadCM3 outputs were not statistically significant on most GCM grids (Fig. 7f). The $50 \mathrm{yr}$ return values for the baseline climate estimated from direct ECHAM and CSIRO outputs (Fig. 7g,j) were much higher than the observed ones, especially on the prairies. Consequently, the projected future values from the direct GCM outputs (Fig. 7h,k) were higher than those in the localized scenarios, although the estimated changes from direct GCM outputs (Fig. 7i,1) were not higher than the localized ones. The changes in direct GCM outputs were not significant on many GCM grids, especially in the CSIRO model.

The $50 \mathrm{yr}$ return values of $\mathrm{T}_{\mathrm{n} \text {-gs }}$ at nearby fine grids estimated from synthetic data were often close to those derived from observed station data for the baseline period (Table 3). However, the values estimated from direct CGCM3 outputs at nearby GCM grids for the baseline period were much lower than those at nearby fine grids, except at Charlottetown and Winnipeg. In contrast, the values estimated from direct HadCM3 outputs at nearby GCM grids for the baseline period were much higher than those at nearby fine grids, except at Fredericton and Ottawa. Higher values were also seen at nearby GCM grids from direct ECHAM and CSIRO outputs for most locations. Estimated changes were not always significant from location to location for the 4 GCM scenarios, based either on direct GCM or localized outputs. This implies that there are considerable uncertainties in future extreme values of the growing season minimum temperature.

\subsection{Growing season maximal daily precipitation $\left(\mathbf{P}_{\mathrm{x}-\mathrm{gs}}\right)$}

The 50 yr return values of $\mathrm{P}_{\mathrm{x} \text {-gs }}$ were often between 50 and $120 \mathrm{~mm}$ across the agricultural region for 1961-1990 (Fig. 8a). The projected changes in the localized scenario of CGCM3 were approximately $20 \%$ higher in most regions, but a slight decrease occurred over Atlantic Canada for 2040-2069 (Fig. 8b,c). More consistent increases for 2040-2069 in the localized scenario of HadCM3 were seen across all regions (Fig. 8d,e). Increases of about 15 to $25 \%$ of the baseline values were also projected from the localized scenarios of ECHAM and CSIRO (Fig. 8f-i) for regions excluding the southwestern part of the prairies. Either an insignificant change or a decrease was estimated for the southwestern part of the prairies from all 4 scenarios. 

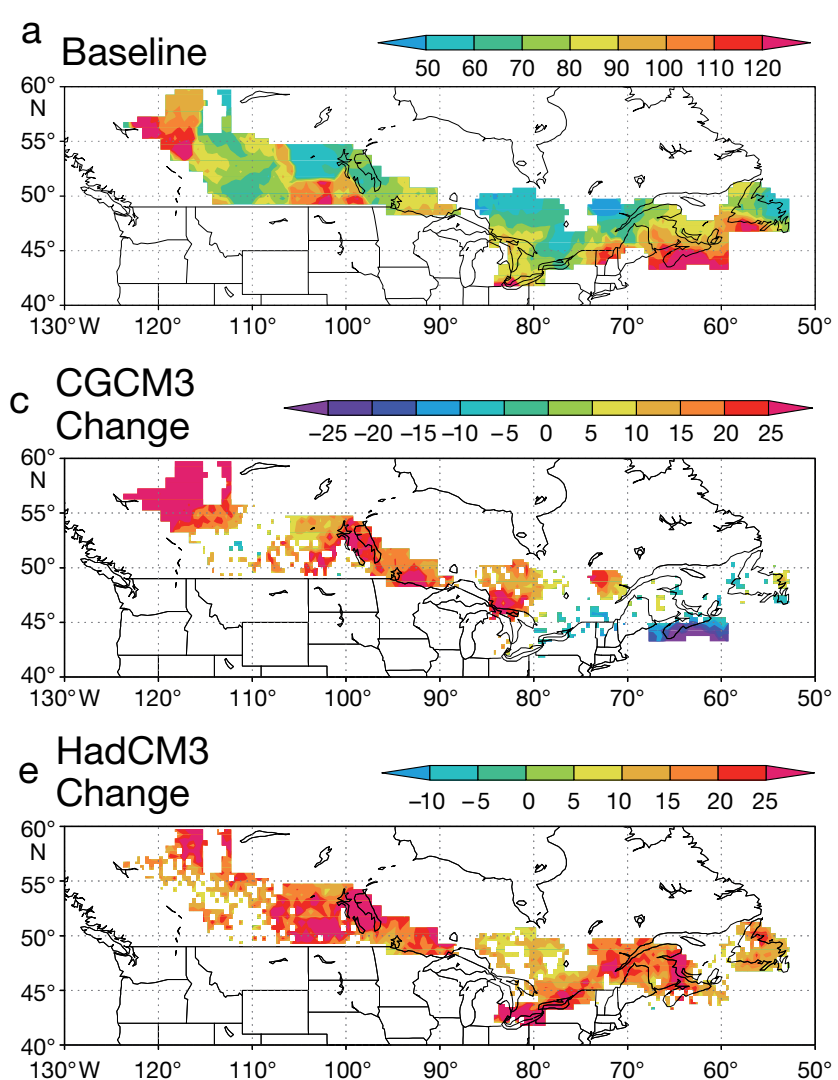

ECHAM
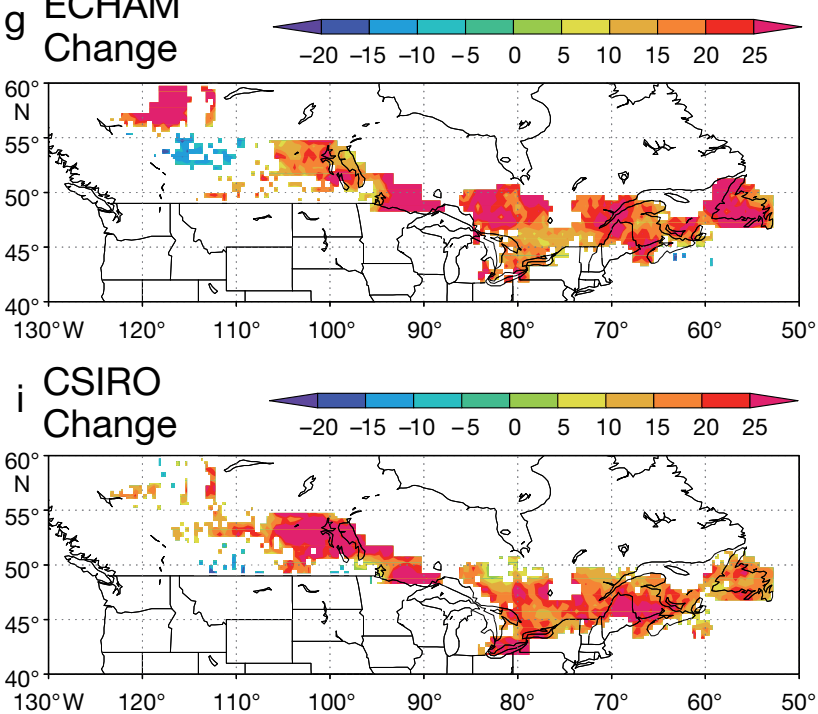

The $50 \mathrm{yr}$ return values of $\mathrm{P}_{\mathrm{x} \text {-gs }}$ on GCM grids in direct GCM outputs of the 4 GCMs (Fig. 9a,d,g,j) were often lower than the observed ones on fine grids for the baseline climate, especially with HadCM3 and CSIRO. This was reasonable since precipitation in the GCMs is treated as average in a GCM grid box. Therefore, it was also not surprising that estimated future values in direct GCM outputs for all 4 scenarios (Fig. 9b,e,h,k)
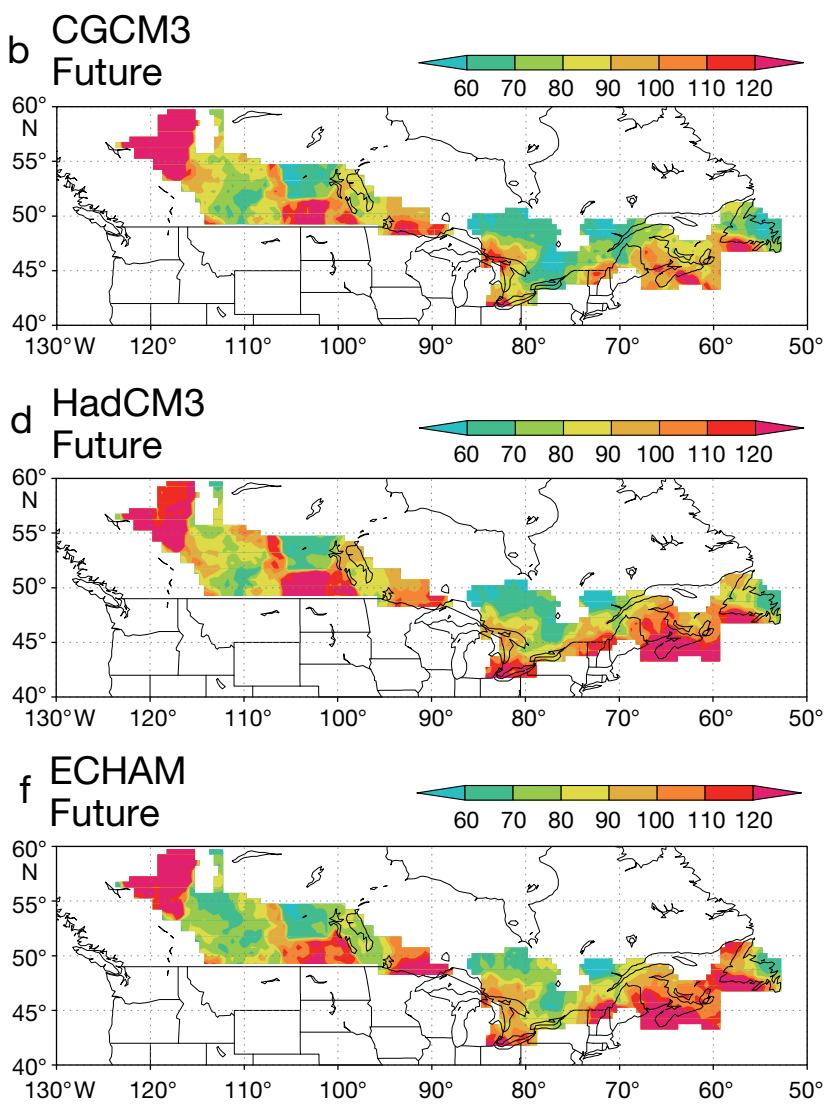

CSIRO

Future

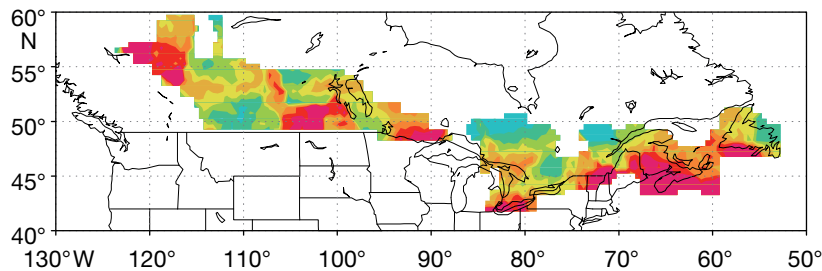

Fig. 8. $50 \mathrm{yr}$ return values $(\mathrm{mm})$ of growing season maximal daily precipitation $(\mathrm{mm})$ for the baseline period (1961-1990) and the localized scenarios of the future period (2040-2069) based on CGCM3, HadCM3, ECHAM and CSIRO as well as the difference between the future and the baseline periods for each scenario (shown as a percentage of the baseline values)

were lower than those in the localized scenarios. Although all 4 models projected an increase at most GCM grids (Fig. 9c,f,i,l), the changes were statistically insignificant at many GCM grids, especially with HadCM3.

The return values of $\mathrm{P}_{\mathrm{x} \text {-gs }}$ derived from synthetic data at nearby fine grids for the baseline period were often close to those estimated from station data (Table 4). 

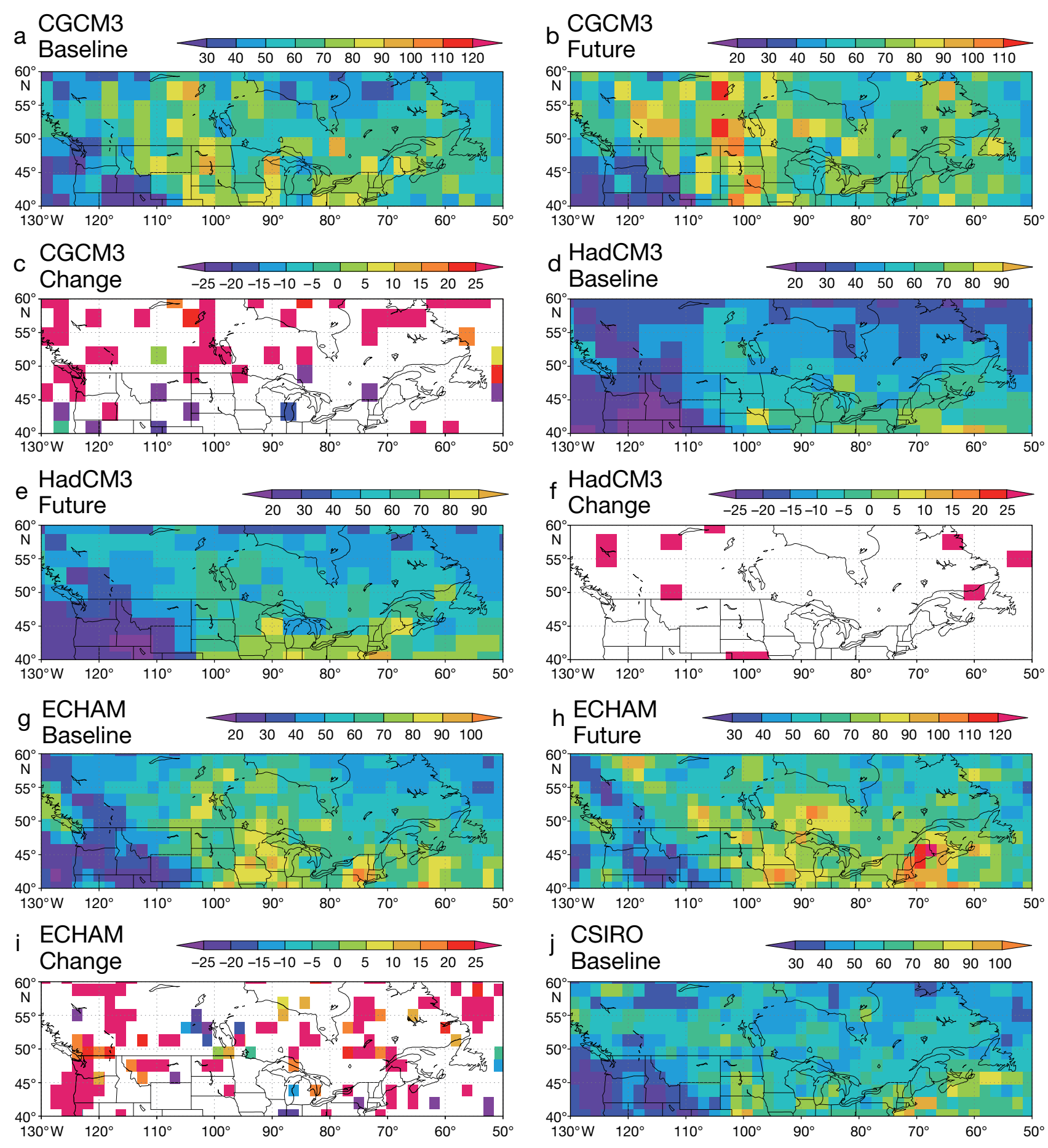

\section{k CSIRO}

Future

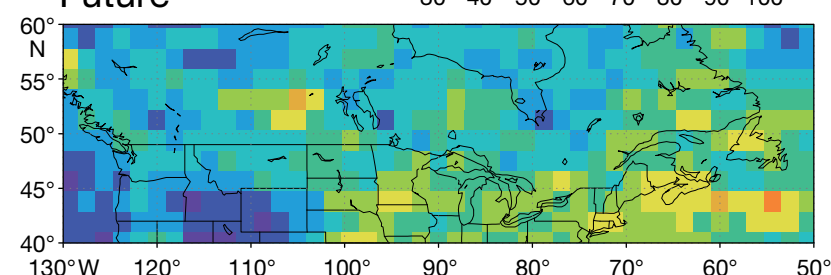

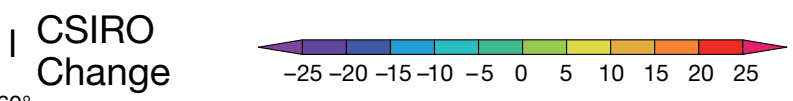

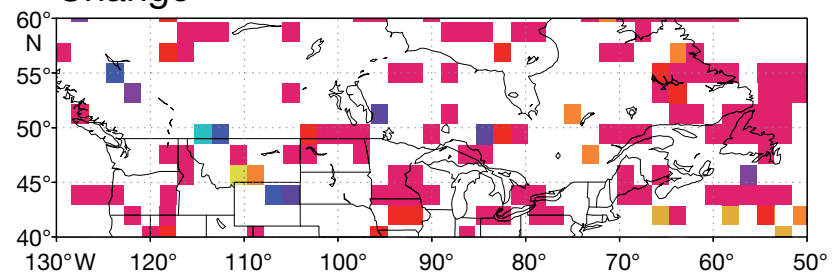

Fig. 9. As Fig. 8, but derived from direct GCM outputs 


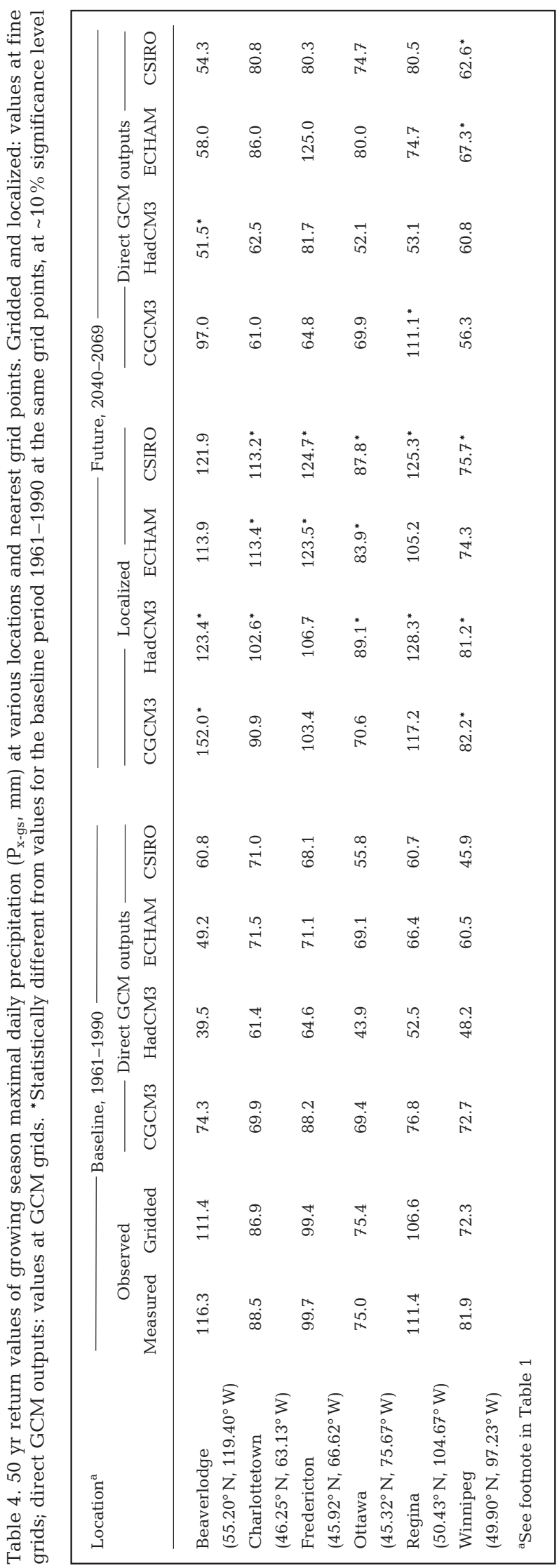

The values from direct GCM outputs for the baseline period were often smaller than those estimated from observations for all 4 GCMs, perhaps because GCM values were averages for the GCM grid boxes. Most projected changes were not statistically significant in direct GCM outputs; however, the majority of estimated changes in the localized scenarios were significant.

\section{DISCUSSION}

Scenarios of climate extremes for 2040-2069 are an important part of inputs to climate change impact studies and the development of adaptation strategies. The scenarios presented in the present study were derived from the localized daily climate scenarios generated by the stochastic weather generator AAFC-WG, based on climate change simulations conducted by 4 GCMs, i.e. CGCM3, HadCM3, ECHAM and CSIRO, forced with the IPCC SRES A2 emissions scenario.

The 4 GCM climate change experiments all indicated a warmer future in either direct GCM outputs or the localized scenarios. The estimated changes in $T_{x-a}$ were significant in the localized scenarios and fairly consistent across the GCMs, although HadCM3 appeared warmer than others. However, extreme values of $\mathrm{T}_{\mathrm{x} \text {-a }}$ for the baseline period were often overestimated, resulting in higher values for the 2040-2069 period in direct GCM (CGCM3, HadCM3 and CSIRO) outputs than in the localized scenarios. Underestimation of $\mathrm{T}_{\mathrm{x}-\mathrm{a}}$ was found in the direct ECHAM outputs for the baseline climate, resulting in lower values for the future period in direct ECHAM outputs than in the localized ones. The localized scenarios may be of help in reducing uncertainties in GCMs' climate projections.

Future changes in the extreme values of $T_{n-a}$ were more dependent on the climate change simulations conducted by GCMs. The changes in $\mathrm{T}_{\mathrm{n}-\mathrm{a}}$ estimated from the localized scenario of CGCM3 were significant, and an increase of 5 to $10{ }^{\circ} \mathrm{C}$ was consistently projected. The simulated changes in $\mathrm{T}_{\mathrm{n}-\mathrm{a}}$ in the localized scenario of CSIRO showed a more consistent increase of $>8^{\circ} \mathrm{C}$. In contrast, the changes in $\mathrm{T}_{\mathrm{n} \text {-a }}$ derived from the localized scenario of HadCM3 were rather different. The projected increase was often $<5^{\circ} \mathrm{C}$, and a decrease was foreseen in the western part of the prairies. Smaller increases on the prairies were also found in the localized scenario of ECHAM. Differences in the 4 model projections highlight the uncertainty in future climate projected by GCM simulations and the need to consider an ensemble of several models to account for a range of outcomes. The return values derived from direct outputs of the 4 GCMs for the baseline period were often not close to the observed 
ones, resulting in differences between the scenarios of extremes for the future in direct GCM outputs and localized scenarios. The return values estimated from the localized scenarios were considered more appropriate than those derived from direct GCM outputs. Furthermore, an insignificant change on a GCM grid could be associated with a significant change at finer grids in the localized scenarios. This fact needs to be taken into account when direct GCM outputs are used to study the potential changes in climate extremes.

The projected increase for the $50 \mathrm{yr}$ return values of $\mathrm{T}_{\mathrm{n} \text {-gs }}$ was mostly $<5^{\circ} \mathrm{C}$ for the $2040-2069$ period. The magnitude of the changes was relatively small compared with those for $\mathrm{T}_{\mathrm{n}-\mathrm{a}}$, and fairly consistent among the $4 \mathrm{GCM}$ projections. The return values derived from direct GCM outputs for the baseline period were often higher than the observed ones in HadCM3, ECHAM and CSIRO. The return values derived from direct CGCM3 outputs for the baseline period were often lower than the observed ones. Mismatches between the modelled baseline values often resulted in differences found between direct GCM outputs and the localized scenarios for the future period, either in the actual values for the future or the changes from the baseline climate to the future period. Changes in the $50 \mathrm{yr}$ return values of $\mathrm{T}_{\mathrm{n} \text {-gs }}$ were the smallest compared with annual maximum and minimum daily temperatures.

The projected changes for extreme values of growing season daily precipitation were fairly consistent across the agricultural regions in the $4 \mathrm{GCM}$ projections. An increase of around $20 \%$ was foreseen in the localized scenarios, except for most parts of the prairies where insignificant change or a significant decrease was projected. The return values for the baseline period derived from direct GCM outputs were often lower than the observed ones, resulting in lower values for the future climate in direct GCM outputs than those derived from the localized scenarios. Increasing precipitation intensity is in agreement with the intensified hydrological cycle in a warmer climate (IPCC 2007).

\section{CONCLUSIONS}

Direct GCM outputs are currently not generally suitable to be used as climate inputs to climate change impact models at local and regional scales, because climate extremes are more likely associated with subgrid processes under certain large-scale climate variability. Similar to the conclusions drawn by Lucio (2004), we found that extremes derived from direct outputs from the GCMs studied here were often incomparable with the observed values of the extremes for the baseline climate, although some model simula- tions did show more promising results. The present study showed that even the changes for the extremes derived from direct GCM outputs might be different from those derived from the localized climate scenarios. Therefore, it may be more appropriate to study changes of climate extremes based on the localized or downscaled climate scenarios rather than on direct GCM outputs studied here. It should also be kept in mind that localization of future climate scenarios could introduce other uncertainties, depending on the techniques applied. Using multiple scenarios may be of help in quantifying the uncertainties associated with GCMs and downscaling approaches. It is also recognised that ongoing developments to GCMs (including increased resolution, and representation of climate variability and extremes) may improve the usability of direct GCM outputs for local-scale impacts studies.

Acknowledgements. The authors are indebted to Dr. H. Hayhoe for his work in developing localized climate scenarios through the weather generator AAFC-WG. We thank A. Bootsma and V. Kirkwood for their comments on an earlier version of the manuscript. Three anonymous reviewers provided considerable suggestions that helped to improve this paper. We acknowledge the Program for Climate Model Diagnosis and Intercomparison (PCMDI) and the WCRP's Working Group on Coupled Modelling (WGCM) for their roles in making the WCRP CMIP3 multi-model data set available. This work was partly supported by the Government of Canada's Climate Change Action Fund. P.F. and J.G. were supported by the Joint UK DECC, Defra and MOD Integrated Climate Programme (DECC/Defra GA01101, MOD CBC/2B/ 0417 Annex C5).

\section{LITERATURE CITED}

Baron C, Sultan B, Balme M, Sarr B and others (2005) From GCM grid cell to agricultural plot: scale issues affecting modeling of climate impact. Philos Trans R Soc Lond B Biol Sci 360:2095-2108

Cai W, Collier MA, Gordon HB, Waterman LJ (2003) Strong ENSO variability and a super-ENSO pair in the CSIRO Mark 3 coupled climate model. Mon Weather Rev 131: $1189-1210$

Carter TR, Parry ML, Harasawa H, Nishioka S (1994) IPCC technical guidelines for assessing climate change impacts and adaptations. Special Report to Working Group II. Department of Geography, University College London, London

Christensen JH, Hewitson B, Busuioc A, Chen A and others (2007) Regional climate projections. In: Solomon S, Qin D, Manning $\mathrm{M}$, Chen $\mathrm{Z}$ and others (eds) Climate change 2007: the physical science basis. Contribution of Working Group I to the fourth assessment report of the Intergovernmental Panel on Climate Change. Cambridge University Press, Cambridge, p 847-940

Coles S (2001) An introduction to statistical modeling of extreme values. Springer, London

Falloon P, Betts R (in press) Climate impacts on European agriculture and water management in the context of adaptation and mitigation-the importance of an integrated 
approach. Sci Total Environ doi:10.1016/j.scitotenv.2009. 05.002

Goddard L, Mason SJ, Zebiak SE, Ropelewski CE, Basher R, Cane MA (2001) Current approaches to seasonal to interannual climate predictions. Int J Climatol 21:1111-1152

Gordon C, Cooper C, Senior CA, Banks H and others (2000) The simulation of SST, sea ice extents and ocean heat transports in a version of the Hadley Centre coupled model without flux adjustments. Clim Dyn 16:147-168

Hansen JW, Jones JW (2000) Scaling up crop models for climate variability applications. Agric Syst 65:43-72

- Hayhoe HN (2000) Improvements of stochastic weather data generators for diverse climates. Clim Res 14:75-87

Hosking JRM (1990) L-moments: analysis and estimation of distributions using linear combinations of order statistics. J R Stat Soc 52B:105-124

Hosking JRM (1992) Moments or L-moments? An example comparing the two measures of distributional shape. Am Stat 46:186-189

Hutchinson MF (1986) Methods of generation of weather sequences. In: Bunting $\mathrm{AH}$ (ed) Agricultural environments. CAB International, Wallingford, p 149-157

IPCC (2007) Climate change 2007: the physical science basis. In: Solomon S, Qin D, Manning M, Chen Z and others (eds) Contribution of Working Group I to the fourth assessment report of the Intergovernmental Panel on Climate Change. Cambridge University Press, Cambridge

Jungclaus $\mathrm{JH}$, Keenlyside N, Botzet M, Haak H and others (2006) Ocean circulation and tropical variability in the coupled model ECHAM5/MPI-OM. J Clim 19:3952-3972

Katz RW (1996) Use of conditional stochastic models to generate climate change scenarios. Clim Change 32:237-255

Kharin VV, Zwiers FW (2005) Estimating extremes in transient climate change simulations. J Clim 18:1156-1173

Kilsby CG, Jones PD, Burton A, Ford AC and others (2007) A daily weather generator for use in climate change studies. Environ Model Softw 22:1705-1719

Kim SJ, Flato GM, Boer GJ, McFarlane NA (2002) A coupled climate model simulation of the Last Glacial Maximum. I. Transient multi-decadal response. Clim Dyn 19:515-537

Kim SJ, Flato GM, Boer GJ (2003) A coupled climate model simulation of the Last Glacial Maximum. II. Approach to equilibrium. Clim Dyn 20:635-661

> Lucio PS (2004) Assessing HadCM3 simulations from NCEP reanalyses over Europe: diagnostics of block-seasonal extreme temperature's regimes. Global Planet Change 44: $39-57$

> Mearns LO, Schneider SH, Thompson SL, McDaniel LR (1990) Analysis of climate variability in general circulation models: comparison with observations and changes in variability in $2 \times \mathrm{CO}_{2}$ experiments. J Geophys Res D 95: 20469-20490

> Mearns LO, Giorgi F, McDaniel L, Shields C (1995) Analysis of daily variability of precipitation in a nested regional climate model: comparison with observations and doubled $\mathrm{CO}_{2}$ results. Global Planet Change 10:55-78

> Mearns LO, Rosenzweig C, Goldburg R (1996) The effects of changes in daily and interannual climatic variability on CERES-Wheat: a sensitivity study. Clim Change 32: 257-292

Editorial responsibility: Peter Gleckler,

Livermore, California, USA
Mearns LO, Rosenzweig C, Goldberg R (1997) Mean and variance change in climate scenarios: methods, agricultural applications, and measures of uncertainty. Clim Change 35:367-396

Meehl GA, Covey C, Delworth T, Latif M and others (2007) The WCRP CMIP3 multi-model dataset: a new era in climate change research. Bull Am Meteorol Soc 88:1383-1394

Nakicenovic N, Swart R (eds) (2000) Special report on emissions scenarios. A special report of Working Group III of the Intergovernmental Panel on Climate Change. Cambridge University Press, Cambridge

Qian B, Gameda S, Hayhoe H, De Jong R, Bootsma A (2004) Comparison of LARS-WG and AAFC-WG stochastic weather generators for diverse Canadian climates. Clim Res 26:175-191

> Qian B, Hayhoe H, Gameda S (2005) Evaluation of the stochastic weather generators LARS-WG and AAFC-WG for climate change impact studies. Clim Res 29:3-21

Qian B, Gameda S, Hayhoe H (2008) Performance of stochastic weather generators LARS-WG and AAFC-WG for reproducing daily extremes of diverse Canadian climates. Clim Res 37:17-33

Racsko P, Szeidl L, Semenov M (1991) A serial approach to local stochastic weather models. Ecol Model 57:27-41

> Richardson CW (1981) Stochastic simulation of daily precipitation, temperature, and solar radiation. Water Resour Res $17: 182-190$

Riha SJ, Wilks DS, Simeons P (1996) Impacts of temperature and precipitation variability on crop model predictions. Clim Change 32:293-311

Semenov MA (2008) Simulation of extreme weather events by a stochastic weather generator. Clim Res 35:203-212

- Semenov MA, Barrow EM (1997) Use of a stochastic weather generator in the development of climate change scenarios. Clim Change 35:397-414

Semenov MA, Barrow EM (2002) LARS-WG: a stochastic weather generator for use in climate impact studies (Version 3.0). User manual. Available at www.rothamsted. bbsrc.ac.uk/mas-models/larswg.php

Semenov MA, Brooks RJ, Barrow EM, Richardson CW (1998) Comparison of the WGEN and LARS-WG stochastic weather generators for diverse climates. Clim Res 10: 95-107

Skelly WC, Henderson-Sellers A (1996) Grid box or grid point: What type of data do GCMs deliver to climate impacts researchers? Int J Climatol 16:1079-1086

Viner D (1996) The Climate Impacts LINK Project. Clim Monit 23:3-5

Wilks DS (1992) Adapting stochastic weather generation algorithms for climate change studies. Clim Change 22: 67-84

Wilks DS, Wilby RL (1999) The weather generator game: a review of stochastic weather models. Prog Phys Geogr 23:329-358

Zhang X, Vincent LA, Hogg WD, Niitsoo A (2000) Temperature and precipitation trends in Canada during the 20th century. Atmos-Ocean 38:395-429

Zhang X, Hogg WD, Mekis E (2001) Spatial and temporal characteristics of heavy precipitation events over Canada. J Clim 14:1923-1936

Submitted: March 4, 2009; Accepted: January 11, 2010

Proofs received from author(s): March 19, 2010 